\title{
Comprendiendo los efectos de las enfermedades del Viejo Mundo en los nativos americanos: la viruela en las Misiones Jesuíticas de Paraguay ${ }^{1}$
}

\author{
Understanding the Effects of Old World \\ diseases on Native Americans: \\ Smallpox on the Jesuit Missions of Paraguay
}

Robert H. Jackson*

\section{Resumen}

Una consecuencia de contacto sostenido entre los europeos y los nativos americanos después de 1492 fue la introducción de enfermedades del Viejo Mundo, como la viruela y el sarampión que causaron mortalidad catastrófica. Algunos estudiosos sostienen que lo que ellos llaman las epidemias "virgin soil" son las que causaban esa mortalidad catastrófica y la disminución de la población en el pasado durante un siglo o más. Según el modelo, las poblaciones nativas finalmente adquieren inmunidades a las nuevas enfermedades y la mortalidad epidémica se hizo menos grave. Este artículo documenta los efectos de las epidemias de viruela en las poblaciones de guaraníes de las misiones jesuíticas del Paraguay, y muestra que en más de doscientos años continuos, de contacto sostenido, la viruela causó una mortalidad desastrosa en el nivel como se postula para las epidemias "virgin soil" en el siglo XVI. El modelo de disminución de la población desde el siglo XVI, tiene que ser re-evaluado a la luz de estos hallazgos.

Palabras clave: demografía, epidemia, jesuitas, reducciones, viruela,

\begin{abstract}
One consequence of sustained contact between Europeans and Native Americans after 1492 was the introduction of Old World diseases such as smallpox and measles that caused catastrophic mortality. Some scholars argue that what they call "virgin soil" epidemics caused catostrophic mortality, and population declines that lasted for a century or more. According to the model, native populations finally built-up immunities

\footnotetext{
${ }^{1}$ Me gustaría agradecer a Carlos A. Page que me proporcionó copias de los documentos originales utilizados en este artículo.

* Investigador independiente, Ciudad de México.
} 
to the new diseases, and epidemic mortality became less severe. This article exams the effects of smallpox epidemics on the Guaraní populations of the Jesuit missions of Paraguay, and shows that more than two hundred years following sustained contact smallpox caused catastrophic mortality on the level as postulated for "virgin soil" epidemics in the sixteenth century. The model of population decline beginning in the sixteenth century needs to be re-evaluated in light of these findings.

Keywords: demography, epidemics, Jesuits, Reductions, smallpox

Recibido: 5 de octubre de 2014

Evaluado: 12 de diciembre de 2014 
El encuentro inicial en $1492 \mathrm{y}$ el contacto permanente entre las poblaciones y grupos de enfermedades del Viejo y el Nuevo Mundo iniciaron un cambio radical en los patrones demográficos de las poblaciones nativas de las Américas. La guerra, los cambios en los patrones de subsistencia, la competencia entre los hombres nativos y europeos de parejas sexuales, y la enfermedad altamente contagiosa contribuyeron al cambio de la población, y en algunos casos la pérdida de población fue catastrófica ${ }^{2}$. La discusión académica de los cambios en los patrones demográficos nativos después de 1492 ha generado un gran debate sobre cuestiones como el tamaño de las poblaciones nativas en contacto, las causas y el grado de pérdida de población o el cambio, y cómo la sociedad nativa se modificó como consecuencia de la transformación demográfica ${ }^{3}$.

Este artículo contribuye a la discusión y el debate sobre las tendencias demográficas de los nativos a partir de 1492, a través del análisis de los efectos de la viruela en las poblaciones de las reducciones jesuíticas del Paraguay situadas en las fronteras de la América española en las tierras bajas de América del Sur en los siglos XVII y XVIII. Nos centramos en las tendencias demográficas en el período de la colonización post-contacto, que fue el período de mayor pérdida de población en muchas áreas en las Américas, y en particular sobre los efectos de las epidemias de viruela y cómo estas epidemias transformaron las poblaciones guaraníes que vivían en las misiones.

La discusión de las epidemias relativamente bien documentadas, como los brotes de viruela en las misiones del Paraguay, proporciona información detallada para evaluar el modelo de epidemias "virgin soil", que ha influido en varias generaciones de interpretación académica de post-conquista, sobre patrones demográficos. Este modelo postula que las poblaciones nativas americanas experimentaron altas tasas de morbilidad y mortalidad como las primeras oleadas de epidemias de viruela y otros contagios repartidos por todo el continente. Los nativos no tenían inmunidad a las nuevas enfermedades y experimentaron un descenso poblacional continuo, hasta por un siglo o más, pero luego se recuperaron gradualmente desde su punto más bajo en algún momento de mediados del siglo XVII ${ }^{4}$. Si bien se carece de información verosímil y detallada sobre la mortalidad epidémica de la mayor parte del siglo XVI, es decir del período después del contacto sostenido y la conquista.

\footnotetext{
${ }^{2}$ Para un estudio útil a los diferentes factores que contribuyen a los cambios de población y la pérdida de población ver Livi-Bacci, 2005 y 2006: 199-232.

${ }^{3}$ Entradas en el debate sobre post-contacto en cambio demográfico incluyen las obras de la llamada escuela de Berkeley (Cook y Simpson, 1948. Simpson, 1950. Borah y Cook, 1960. Cook y Borah, 19711979). Estos últimos examinaron la evolución demográfica de México y otras zonas en las Américas. En el centro de México Cook y Borah postularon una continua disminución de la población de contacto sostenido y la conquista en 1519 a mediados del siglo XVII, cuando la población nativa llegó a su punto más bajo. Las obras de Simpson, Cook y Borah tienen sus partidarios y detractores, las obras de algunos de los cuales aparecieron en Denevan, 1976/1992. Los debates más acalorados se han centrado en el tamaño de las poblaciones nativas en contacto, que generalmente se utiliza para estimar el grado de pérdida de la población nativa. Ver Henige, 1978: 217-37 y Rosenblat, 1967; 1935: 115-134 y 1976: 4366; Sanders, 1976: 85-150; Zambardino, 1978: 700-708 y 1980: 1-27.

${ }^{4}$ La iteración más reciente de esta interpretación en Cook, 1998: 207. Cook afirma que los niveles de mortalidad fueron consistentemente por encima hasta cuatro generaciones. Sin embargo, la reconstrucción de una cronología de las epidemias, que es la más que los académicos pueden esperar a hacer la mayor parte del siglo XVI, no proporciona evidencia de las tasas de mortalidad de las epidemias.
} 
El análisis de los patrones demográficos y las crisis de mortalidad en las misiones del Paraguay ofrece información que contribuye a la comprensión de los patrones demográficos posteriores a la conquista de América, y en particular de las consecuencias a corto y largo plazo de las crisis de mortalidad catastróficas causadas por epidemias y otros factores. El guaraní se congregó en las misiones de Paraguay. Vivían en sociedades basadas en clanes, y se practicaba la agricultura complementada por la caza y la recolección de alimentos vegetales silvestres. Al mismo tiempo, las poblaciones de las misiones del Paraguay también mostraron diferentes tendencias, y específicamente los diferentes patrones de mortalidad epidémica. Había, por ejemplo, variaciones considerables en las tasas de mortalidad epidémica entre las comunidades, y diversos factores determinaron cuántas personas murieron. Los factores importantes que determinan los niveles de mortalidad incluyeron la estructura por edad y sexo de la población, el tipo y frecuencia de los contactos entre las poblaciones de misión y otros asentamientos, patrones de asentamiento, y la eficacia de las respuestas a la epidemia de contagio.

Las misiones del Paraguay estaban vinculadas a otros asentamientos por varios ríos utilizados para el transporte de personas y mercancías, y que también facilitaron la propagación del contagio. Por otra parte, el Río de la Plata era una frontera colonial impugnada; a partir de una fecha temprana los jesuitas organizaron una milicia en las misiones que sirvió en la campaña para numerosas ocasiones. La movilización y el traslado de las tropas españolas y de milicianos guaraníes, también facilitaron la propagación del contagio. Más de un siglo después del primer contacto sostenido con los europeos, las poblaciones guaraníes de las misiones del Paraguay sufrieron una mortalidad dramática durante las epidemias, y los niveles de mortalidad en las misiones individuales en la escala de lo que se ha postulado para epidemias "virgin soil" en el siglo XVI. Como Massimo Livi-Bacci señala, un análisis de epidemias entre las poblaciones guaraníes de las misiones del Paraguay en el siglo XVIII muestra que: "differences in epidemic mortality between "virgin" and "non-virgin” populations were much smaller than is commonly assumed, and the actions of the Europeans mattered a great deal (las diferencias en la mortalidad entre epidemia "poblaciones vírgenes" y "novirgen" eran mucho más pequeños de lo que comúnmente asumieron, y las acciones de los europeos importaban mucho)" 5 .

Este artículo documenta los efectos de las epidemias de viruela en estas poblaciones. Por otra parte, valoramos y discutimos las interpretaciones recientes de los patrones demográficos y las consecuencias de los patrones de mortalidad en las misiones del Paraguay. Algunos estudiosos intentan analizar los patrones demográficos utilizando medidas simplistas de cambio, como la diferencia porcentual entre la población durante un período de tiempo ${ }^{6}$. La única información que este ofrece es que las diferentes cantidades de personas, según los informes, vivían en una comunidad en

\footnotetext{
${ }^{5}$ Livi-Bacci, 2006: 225.

${ }^{6}$ En un libro de reciente publicación, Julia Sarreal (2014: 142-147) analizó el crecimiento de la población en el periodo post-jesuita y la disminución de la expulsión sobre la base de datos en su Tabla 6 que registra la población en cinco años entre 1768 y 1801, el cambio porcentual medio entre cada conteo de la población, y el porcentaje total de cambio entre 1768 y 1801. Estos datos no contienen pruebas que las generalizaciones sobre la población "crecimiento" o "me niego" por el contrario, en un período de la emigración como miles de guaraníes decidieron dejar las misiones, los datos de la Tabla 6 son meros documentos que un número mayor o menor de personas estuvieron presentes en la misión en el día del recuento de la población.
} 
las fechas cuando un empleado del censo les enumeró. Como argumenté en un estudio previo, el análisis de los patrones demográficos en las misiones jesuíticas del Paraguay se basa primordialmente en la reconstrucción de las tasas vitales, utilizando registros que proporcionan números de nacimientos/bautizos, matrimonios y defunciones, y la interpretación de los efectos de las epidemias en la poblaciones guaraníes de las misiones ${ }^{7}$. Un estudio demográfico seminal titulado The Population History of England, 1547-1871: A Reconstruction, tenía una base en el análisis exhaustivo de la información de los registros de nacimientos, matrimonios y defunciones utilizados para reconstruir las tasas vitales en el tiempo ${ }^{8}$.

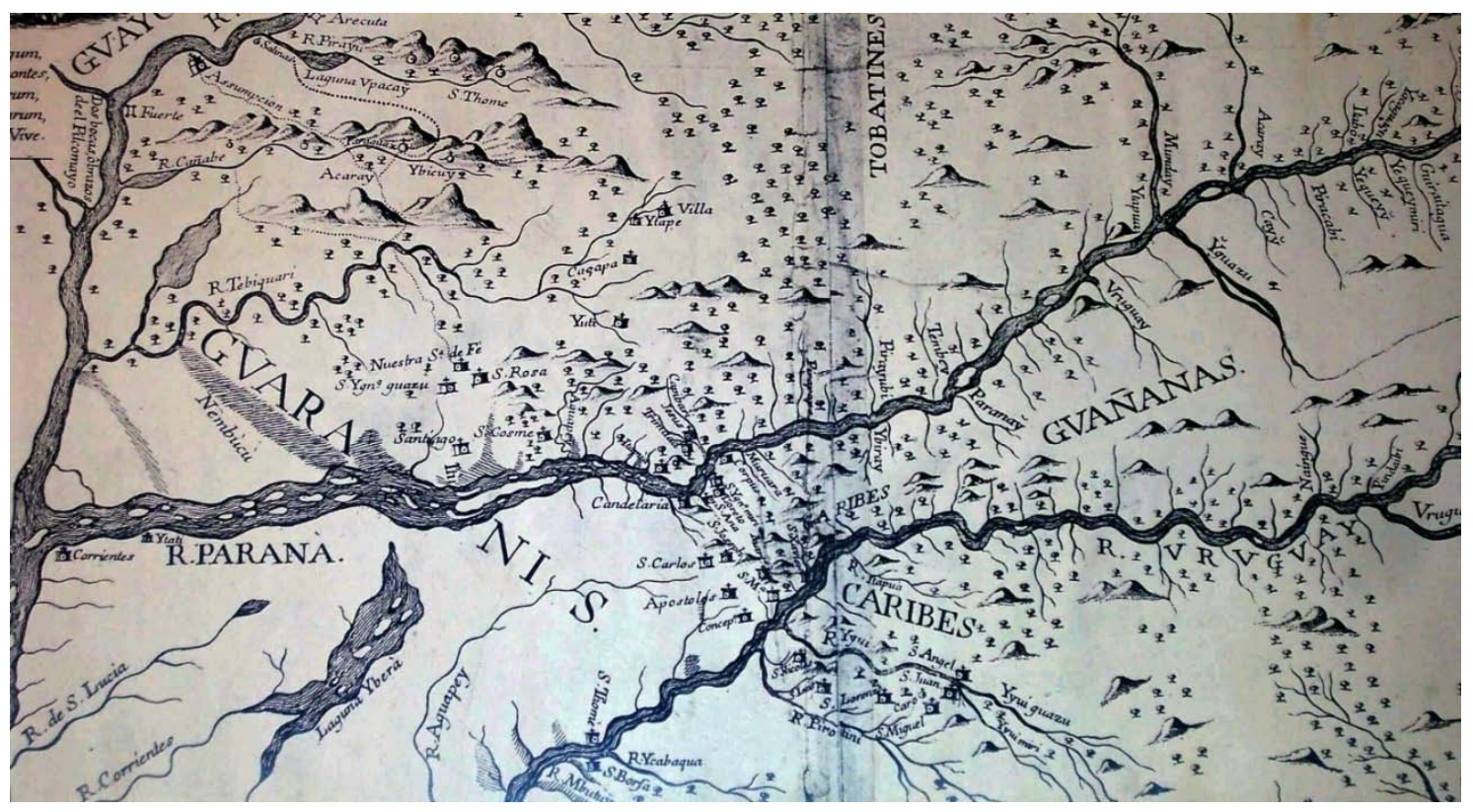

Mapa 1: Un mapa contemporáneo de las misiones de Paraguay que muestran grupos nativos. Biblioteca del Congreso Mapa División de Geografía y Mapas, Washington, D.C.

\section{Construyendo casas en la arena: Una reconsideración de cambios demográficos en el Siglo XVI.}

El siglo XVI, inevitablemente, es el punto de partida para cualquier discusión de los patrones de la evolución demográfica de las poblaciones nativas. Sin embargo, irónicamente este es el período con la menor cantidad de información fiable sobre las tasas vitales y los efectos de las epidemias. La evidencia simplemente no existe, y esto es particularmente cierto para las primeras generaciones siguientes de contacto sostenido y la conquista. Por otra parte, muchas interpretaciones de los patrones demográficos en el siglo XVI se basan en hipótesis que no se demuestran con hechos lo suficientemente robustos para ser sometidos a un análisis crítico. México es un ejemplo de ello. No hay duda que en 1519 México tenía una población numerosa, y que las crisis de mortalidad causaron la disminución de las poblaciones nativas. Sin embargo, el primer censo razonablemente confiable de la población era un censo de tributarios de

\footnotetext{
${ }^{7}$ Jackson, 2008: 401-431.

${ }^{8}$ Wrigley y Schofield, 1981. Muchos eruditos que escriben sobre temas de los patrones demográficos de nativos americanos después del contacto sostenido y la conquista no hacen referencia a la extensa y sofisticada literatura de los patrones demográficos europeos en la época moderna temprano.
} 
los años 1560. Los estudiosos han utilizado otras fuentes mucho menos fiable como la suma de visitas, un documento que resume los informes de tributo en ciertas jurisdicciones del centro de México, para hacer lo que solo puede ser considerado como estimaciones del tamaño de la población nativa en contacto ${ }^{9}$. Sherburne Cook y Woodrow Borah intentaron sacar datos confiables de un documento muy deficiente para proporcionar la base estimativa del tamaño de la población de contacto, pero la inconsistencia en las categorías informadas no podían superarse, excepto al hacer ciertas suposiciones sin fundamento que socavaron la validez de sus conclusiones ${ }^{10}$.

La cuestión de los efectos de las epidemias de enfermedades altamente contagiosas, tales como la viruela es aún más problemática en el siglo XVI, dada la escasez de información cuantificable y fiable. El registro de las primeras epidemias en el centro de México, por ejemplo, se basa principalmente en la descripción de los síntomas y observaciones, que no ofrecen el mismo grado de fiabilidad para hacer generalizaciones sobre la morbilidad epidémica y las tasas de mortalidad. Uno de los documentos, de 1580, describió la pérdida de población en la jurisdicción de Tepeaca (Puebla). El informe señaló que "... hoy de la gente que estaba [aquí] cuando los españoles entraron en [el país], de 109 [faltan]"11. Estas generalizaciones no son lo suficientemente sólidas como para hacer afirmaciones sobre la mortalidad de las epidemias y las tasas de la despoblación en el tiempo, ya que algunos estudiosos lo han hecho. Henry Dobyns, por ejemplo, utilizó información endeble o inexistente para argumentar que las tasas de mortalidad de las epidemias, eran uniformes sobre grandes territorios ${ }^{12}$. Los datos de las misiones jesuíticas del Paraguay y otros estudios de casos basados en las fuentes más confiables muestran que existe una considerable variación en las tasas de mortalidad entre las comunidades y poblaciones.

Los diferentes tipos de poblaciones respondieron a las crisis de mortalidad de distintas maneras, y uno de los elementos que faltan en la discusión de los cambios en la población del siglo XVI, es si las poblaciones nativas se recuperaron tras la alta mortalidad de las epidemias. Un segundo elemento ignorado en muchas construcciones, y esto sin duda es el caso de las interpretaciones de Dobyns, son los efectos de las epidemias en poblaciones sedentarias contra las no sedentarias. Las poblaciones guaraníes en las misiones jesuíticas del Paraguay, por ejemplo, se recuperaron tras las graves crisis de mortalidad. Otras poblaciones que no lo hicieron, y pequeños grupos de cazadores y recolectores nómadas eran particularmente vulnerables a la extinción cultural y biológica. Un ejemplo son las poblaciones pames de las misiones franciscanas establecidos en la región de la Sierra Gorda de México en 1744. Los pames habían vivido previamente en un patrón de asentamiento disperso en una zona montañosa accidentada, un patrón que amortiguaba los efectos de las epidemias. Entre $1744 \mathrm{y}$ 1746, los franciscanos congregaron a más de 7.000 pames en cinco misiones. Las epidemias mataron a cientos de pames, y las muertes superaron a los nacimientos ${ }^{13}$. Muchos de los sobrevivientes regresaron a pequeñas aldeas en las montañas,

\footnotetext{
${ }^{9}$ Del Paso y Troncoso, 1905.

${ }^{10}$ Cook y Borah, 1960.

${ }^{11}$ Del Paso y Troncoso, 1905: 19.

12 Dobyns, 1983.

13 Jackson, 2013: 46-91.
} 
abandonando los sitios de las misiones del valle con el implícito esfuerzo de cambiar su forma de vida.

Otro factor relacionado al que se presta poca atención en la consideración de la post-conquista, el cambio demográfico y los efectos de la mortalidad epidémica, es la estructura de género de una población. La población guaraní que vivía en las misiones no experimentó desequilibrios de género que contribuyeron al colapso de la población de otras poblaciones. En otras palabras, aún había un gran número de mujeres en edad de procrear, siguientes a la crisis de mortalidad. La población de la misión de Santa Cruz en California es un ejemplo de un caso extremo de lo contrario, de desequilibrio de género. De 1791 a 1833, los franciscanos bautizaron 1.133 niñas y mujeres en la misión. Sin embargo, en 1833, sólo 87 mujeres permanecieron en la misión, y constituían sólo el 31\% de la población total ${ }^{14}$. Las mujeres y las niñas constituyen al menos la mitad de la población de las misiones guaraníes, incluso después de las crisis de mortalidad graves. Los patrones demográficos para las dos poblaciones eran muy diferentes, y la población de la misión de Santa Cruz experimentó cerca de la extinción biológica y cultural.

El modelo de epidemias "virgin soil", y disminución de la población continua después del contacto sostenido y conquista, necesita ser modificado a la luz de la evidencia basada en datos más detallados, en particular en los patrones de mortalidad epidémica. Como señala Livi-Bacci, en algunos casos la mortalidad epidémica del siglo XVIII llegó a los mismos o similares niveles, como postulado por los defensores del modelo de "virgin soil", y tan alto como 50 ó 60 \% de la población de las comunidades de misión individuales. Estas epidemias, en particular los brotes de viruela letales, mataron a miles de guaraníes a unos 150 a 200 años después del contacto sostenido y la conquista. La idea sobre que las poblaciones nativas construyeron inmunidades con el tiempo y se recuperaron, no resiste a la luz de la evidencia de la continua alta mortalidad en las misiones del Paraguay. Más bien, las epidemias se produjeron alrededor de una vez a una generación, y mataban la población de la joven nacida desde el brote anterior. Otro factor que a menudo no se considera es la respuesta médica a los brotes epidémicos. La siguiente sección examina la teoría de la enfermedad del siglo XVIII y su tratamiento.

\section{Teoría y tratamiento de enfermedades.}

La teoría de los gérmenes que atribuye las causas de muchas enfermedades a las bacterias y a los virus, no ganó aceptación general entre los médicos hasta finales del siglo XIX. Los misioneros jesuitas mismos atribuyen epidemias a Dios, y creían que el contagio fue enviado como castigo o misericordia para llevar a los verdaderos creyentes al cielo. Los ignacianos a menudo organizaban procesiones para aplacar la ira, además de implementar métodos prácticos que intentaron limitar la mortalidad. Cuarentena, por ejemplo, tenía una larga historia en Europa, y fue un método común empleado por los jesuitas durante las epidemias ${ }^{15}$. Sin embargo, muchos guaraníes veían la cuarentena

\footnotetext{
${ }^{14}$ Jackson, 1994: 113.

${ }^{15}$ Guillermo Furlong, 1962: 612. La Carta Anua de 1632-1634 documentó la aplicación de medidas de cuarentena durante un brote de viruela en las misiones de Paraguay 1631-1633. El informe señaló: "Aunque la peste general y cruel que ubo en año de 32 hizo muy grande razia en casi todas las reducciones, esta [San Nicolás de Pyratini] por particular beneficio del Señor se escapó con muy poco
} 
con sospecha, y se escondía a miembros de la familia para evitar que fueran enviados a los hospitales ${ }^{16}$.

El tratamiento médico en los siglos XVII y XVIII tenía una base en las teorías de húmero y miasma. Al mismo tiempo, algunos médicos emplearon otros tratamientos como la inoculación por variolación desarrollado a través de la observación de las víctimas de la viruela, o prácticas populares alternativas. La teoría del húmero se basa en antiguas ideas griegas, y ve la enfermedad como consecuencia de los desequilibrios en los cuatro humores básicos (sangre, flema, cólera y melancolía) ${ }^{17}$. Sangría, la extracción de sangre era un tratamiento empleado para reducir la fiebre, y tenía una base en la creencia de que la fiebre era una manifestación de sangre caliente y podría paliarse mediante la extracción de sangre. La teoría de los miasmas sostuvo que la enfermedad resultó de nubes de gases tóxicos que emanaban de los cuerpos en descomposición, vegetación u otro material orgánico. Un método usado para limitar la propagación del miasma era enterrar cuerpos profundamente en el suelo para evitar el escape de gas tóxico ${ }^{18}$.

La inoculación por variolación era un método de tratamiento derivado de la práctica popular en China y el Medio Oriente, y fue introducida en Europa a principios del siglo XVIII. Esto consistía en tener pus de una pústula de viruela, e inyectarlo en el cuerpo de un individuo sano para provocar una infección leve. Los médicos en la ciudad de México emplearon primera inoculación por variolación durante un brote de viruela 1779. Allí, los funcionarios reales difunden información sobre el tratamiento de otras partes de Nueva España. Misioneros dominicos en las misiones de Baja California, por ejemplo, inocularon nativos en varias misiones y redujeron significativamente la mortalidad durante una epidemia de viruela, mientras que los misioneros en otras misiones no lo hicieron y la mortalidad en ellas fue mucho mayor ${ }^{19}$. El primer caso registrado de la aplicación de la inoculación por variolación en las misiones del Paraguay fue durante las epidemias de viruela 1785-1786. Diez años más tarde, en 1796, un médico en Yapeyú inoculó 126 guaraníes en la cercana misión de San Francisco de Borja, de que murieron quince. El médico atribuyó estas muertes (doce por ciento de los inoculados) a las complicaciones de otras infecciones, enfermedad venérea en particular que debilitaron los sistemas inmunológicos de las personas que murieron ${ }^{20}$.

\footnotetext{
daño suio a que aiudo mucho la industria y solicitud del Padre Silverio Pastor que la tuvo a su cargo, y viendo saltar en ella unas como centellas de aquel furiosísimo incendio hizo levantar media legua fuera del pueblo unas chosas acomodadas donde hazia llevar con grande diligencia todos los que se sentían tocados y diputándoles un Alcalde del pueblo que siempre les asistiesse y diligentes enfermeros que les sirviesen y diessen aviso al Padre de todas sus necesidades espirituales y corporales. Puso gran cuidado que ninguno otro aunque fuesen de sus parientes les visitasse por se el mal tan contagioso con lo qual no murieron sino siete u ocho, que fue singular misericordia de Nuestro Señor...” Maeder, 1990: 150.

${ }^{16}$ Los funcionarios reales en Apóstoles, por ejemplo, informaron que los guaraníes escondieron las víctimas de la viruela para impedir que sean enviados al hospital plaga. Ver Expediente s[ob]re la Epidemia de Viruelas q[u]e acometió a los Pueblos de S[an] Joséph y Apóstoles, Archivo General de la Nación, Buenos Aires, Sala 9-8-3-52.

17 Jackson, 2004: 346.

${ }^{18}$ Para una discusión general de la demografía y las teorías de la enfermedad y su tratamiento ver Flinn, 1980 y Jackson, 1994.

19 Jackson, 1981: 138-143.

${ }^{20}$ Furlong Cardiff, 1962: 609.
} 
En 1798 la publicación del médico inglés Edward Jenner describió una nueva vacuna contra la viruela. Jenner había observado que las criadas de la leche en la Inglaterra rural no contrajeron la viruela, y concluyó que, debido a que entraron en contacto con las vacas infectadas con viruela vacuna, ésta causó una infección leve en los seres humanos que han adquirido un grado de inmunidad a la viruela. Se vacunó con éxito a un niño con una vacuna de la viruela vacuna en 1796, publicando los resultados de su investigación dos años más tarde. Los funcionarios españoles introdujeron la nueva vacuna a través de la expedición médica Balmis para las Américas, en la primera década del siglo XIX (1803). La expedición llevaba la nueva vacuna de la viruela vacuna en los cuerpos de niños. Los médicos a su vez vacunaron otros niños con pus de las pústulas viruela de las vacas que se desarrollaron en los brazos de los mismos, e introdujeron la vacuna en toda la América española por la transmisión de un brazo a otro. La expedición también distribuye traducciones al español del informe que describe las observaciones y hallazgos de Jenner ${ }^{21}$.

Una campaña mundial erradicó la viruela en el siglo XX, con el último caso natural reportado en Somalia en 1977. Durante los siglos XVII y XVIII el contagio mató a miles de guaraníes en las misiones del Paraguay, y las técnicas utilizadas para combatir la enfermedad eran generalmente ineficaces. Las siguientes secciones documentan casos de estudio de la mortalidad de la viruela. La primera es de un brote en los años 1738-1740 que fue el tercero de una serie de epidemias durante la década que mató a miles de personas. El segundo es de un brote de 1763-1765 que se produjo durante un período de crisis. El tercer caso es de un brote letal en Yapeyú en 1770-1772. Yapeyú fue uno de los más poblados de las misiones. Las epidemias se produjeron en un contexto de conflicto entre España y Portugal por el control del Río de la Plata fronterizo en disputa, y la participación de las misiones del Paraguay en el comercio regional, sobre todo a lo largo de los ríos navegables de la región.

\section{La epidemia de la viruela 1738-1740.}

Tres epidemias diezmaron a la población de las misiones del Paraguay durante la década de 1730, y la más letal fue la viruela que mató a miles entre 1738 y 1740 . Una conjunción de factores contribuyó a las crisis de grave mortalidad de la década de 1730 . Una epidemia se extendió a través de las misiones en 1733 matando a unos 19.000 nativos. Las tasas de mortalidad más altas fueron en San Ignacio Guazú, Santa Rosa y Nuestra Señora de Fe, las misiones situadas más cerca de la zona donde se enviaron los milicianos $^{22}$. Hacia el final de 1734 el gobernador de Paraguay solicitó un gravamen de otros 12.000 guaraníes milicianos cristianos. A principios de 1735 el primer contingente de 6.000, continuó la campaña en la región cerca del río Tebicuarí, y otros 6.000, según los informes, se fueron después. En 1735, el gobernador de Buenos Aires Miguel de Salcedo ordenó la movilización de 3.000 guaraníes de milicia adicional para una posible campaña contra el puesto portugués de Colonia del Sacramento ${ }^{23}$. El sarampión mató a

\footnotetext{
${ }^{21}$ Fernández del Castillo, 1985.

${ }^{22}$ Entierros en Guazú totalizaron 1.192 durante 1733, y una tasa bruta de mortalidad por mil población de 509. La población de la misión se redujo de 3.195 a finales de 1731 a 1.266 en 1733. Los entierros fueron de 2.263 en Santa Rosa, y una tasa bruta de mortalidad de 459.2. La población se redujo de 6.093 en 1731 a 2.775 a finales de 1733 . Los jesuitas de La Fe registró 2.618 entierros, o una tasa bruta de mortalidad de 389,4. La población se redujo de 6.515 en 1731 a 4.251 en 1733.

${ }^{23}$ Carbonnel de Masy, 1992: 359.
} 
miles de personas en las misiones entre 1735 y 1736, y la situación de hambruna y fuga de las misiones de muchos guaraníes que iban en busca de comida, junto con el movimiento de tropas y el tráfico fluvial, facilitó la propagación del contagio. La viruela se extendió a través de las misiones varios años más tarde, a partir de 1738 y entró en las misiones desde Asunción y se extendió a lo largo del río Uruguay.

De acuerdo con la Carta Anua 1735-1743, la escasez de lluvias desde diciembre de 1733 a marzo de 1734 dañó los cultivos, y muchas de las misiones no tenían grandes cantidades de ganado como una fuente alternativa de alimento. También hubo una epidemia en el ganado en 1735, y en el mismo año las tropas coloniales portugueses ocuparon la Vaquería de Pinares, un área donde pastaban unas 230.000 reses bravas y que las misiones aprovechado para reponer sus rebaños. Por otra parte, los portugueses atacaron pastores enviados por los jesuitas estacionados en la misión de San Luis Gonzaga para arrear el ganado cerca del mar en la zona fronteriza en disputa. Las temperaturas heladas durante las noches del 20, 21 y 22 de agosto de 1734, durante la temporada de siembra, redujo aun más la producción de cultivos, aunque abundantes lluvias en noviembre y diciembre de 1734 prometían mejores cosechas. A la vez, el mismo documento señala condiciones de sequía en las misiones ubicadas más cerca de Asunción, donde los funcionarios reales habían asentado a las milicias guaraníes. Los jesuitas también informaron que los guaraníes comieron los granos, lo que redujo aun más la producción de cultivos y prolongó la hambruna. La necesidad de abastecer a la milicia sólo exacerbaba el sufrimiento de los que se quedaban en las misiones ${ }^{24}$.

La hambruna en 1734 y 1735 siguió los pasos de la epidemia en 1733. La mortalidad en 1734 ascendió a 10.130 según los informes, incluyendo 6.094 párvulos (niños hasta la edad de nueve o diez años), y miles de guaraníes huyeron en busca de alimento. La Carta Anua señaló que 8.022 residentes de la misión eran fugitivos en 1735, y que un grupo de ellos establecieron una comunidad cerca de Laguna de Yberá cerca de la frontera del territorio de las misiones. El movimiento de miles de guaraníes facilitó la propagación de la epidemia de sarampión a través de la región en 1735 que mató a miles (ver Cuadro 1$)^{25}$.

La mortalidad total en las treinta misiones, según informes, alcanzó 18.013 en 1738, 12.592 en el año siguiente, y 4.499 en las últimas etapas de la epidemia en 1740. Además, el número de bautismos (nacimientos) disminuyó de 4.618 en 1738 a 3.452 en 1739. La viruela cobró la vida de miles de personas, y también redujo las tasas de natalidad. La población de las misiones se redujo de 104.473, reportado al cierre de 1737, a 73.910 a finales de 1740 , cuando ya no había suficiente potencialmente huéspedes susceptibles para mantener la cadena de infección ${ }^{26}$.

\footnotetext{
${ }^{24}$ Littre Annuae Provincia Paraguarie Anno 1735, Archivum Romanum Societatis Iesu, Vatican City.

${ }^{25}$ Ibid. Antes de su difusión a las misiones de Paraguay en 1735, el sarampión mató a miles de personas en las ciudades de la región. La carta anua informó que 12.000 personas murieron en Buenos Aires, y Penitentes en Asunción recurren a la autoflagelación para aplacar la ira de Dios que ellos creían responsable del brote de contagio. Los movimientos de tropas y el diáspora Guaraní durante la hambruna, facilitaron la propagación de la epidemia, como la gente en movimiento llevaron la enfermedad en sus cuerpos. No hay evidencia para apoyar la interpretación común que las víctimas del hambre, son más susceptibles a la enfermedad debido a la debilitación de sistema inmunológico del cuerpo.

${ }^{26}$ Carbonell de Masy, 1992: 377-378.
} 
Si la mortalidad se mide por las poblaciones combinadas de las 30 misiones (medido como la tasa bruta de mortalidad por cada mil habitantes, el número total de muertes en relación con la población total $=$ TBM), la epidemia no parece haber sido uno de los brotes más graves de la historia de las misiones del Paraguay. La TBM en 1738 para las poblaciones combinadas fue 171,1, en 1739 fue 139,5, y en 1740 se redujo a 60,5. Sin embargo, la mortalidad varió significativamente entre las misiones e incluso entre los establecimientos de las inmediaciones; y las tasas de mortalidad en las misiones individuales durante este brote, alcanzaron niveles que se encontraban entre las más altas registradas para las misiones del Paraguay. La variación en los niveles de mortalidad se puede ver, por ejemplo, en el número de muertes registradas en 1738 en Candelaria y Santos Cosme y Damián, situados en ese momento en un sitio cerca de Candelaria, en la orilla oriental del río Paraná. Los jesuitas registraron un total de 1.528 entierros (TBM de aproximadamente 496,0) en Candelaria, y sólo 318 (TBM de aproximadamente 207,7) en el Santos Cosme y Damián. Muertos en San José los informes, totalizaron 1.874 en el mismo año, 2.262 en Apóstoles, y 2.168 en Concepción $^{27}$. Del mismo modo, las tasas de mortalidad en 1739 fueron significativamente diferentes en Los Santos Mártires del Japón y en Santa María la Mayor, llegando a 184,2 en la primera misión mencionada donde los jesuitas registraron 545 muertes, frente un TBM de 565,4 y 1.279 muertes en Santa María (ver Cuadro 2) ${ }^{28}$.

La mortalidad parece haber sido particularmente grave entre 1739 y 1740 en varias de las misiones orientales, las ubicadas a lo largo y al este del río Uruguay en lo que hoy es Río Grande do Sul, Brasil. En 1739, por ejemplo, 2.681 guaraníes murieron en San Lorenzo (TBM de 557,0), 2.396 en San Luis Gonzaga (TBM de 565,1), 1.675 en San Nicolás (TBM de 336,8), y 1.605, en La Cruz (TBM de 416,6). Hacia 1740, la viruela había terminado en la mayoría de las misiones, pero alcanzó su pico en San Juan Bautista, donde 2.400 guaraníes murieron (TBM de 485,0). Varias misiones vecinas, San Miguel y Santo Ángel Custodio, por otro lado, no experimentaron una fuerte mortalidad durante la epidemia de la viruela, medida por los cambios en los niveles de población. Las poblaciones de San Luis Gonzaga, San Nicolás y San Lorenzo Mártir disminuyeron de 4.327 a 1978, 5.071 a 1772, y de 4.814 a 974, respectivamente, entre 1738 y 1739, y la población de San Juan Bautista se redujo de 4.949 en 1739 a 2.171 en al año siguiente. Las poblaciones de San Miguel y Santo Ángel Custodio, por su parte, crecieron entre 1738 y 1740 de 4.522 a 4.740 y desde 4921 a 5.228, respectivamente ${ }^{29}$. Los jesuitas estacionados en estas dos misiones geográficamente aisladas, pueden haber puesto en marcha medidas eficaces de cuarentena, lo que obviamente no funcionaba en la mayoría de las otras misiones de Paraguay.

Un detallado padrón de tributarios de 1759 de la misión de Corpus Christi es una prueba más que las consecuencias demográficas de la epidemia de la viruela, siguen siendo evidentes en la década de 1730. Los misioneros que prepararon el censo proporcionan un tipo de información que normalmente no aparece en los recuentos de población similares: la fecha de bautismo de cada guaraní. La inclusión de esta información permite una reconstrucción inusualmente precisa de la estructura por edad y sexo de la población en un momento dado en el tiempo. La estructura de edad

\footnotetext{
${ }^{27}$ Carbonell de Masy; Blumers y Levinton, 2003: 145. Littre Annuae Provincia Paraguarie Anno 1735, Archivum Romanum Societatis Iesu, Ciudad Vaticano.

${ }^{28}$ Jackson, 2004b: 2-23 y 2005: 475.

${ }^{29}$ Ibíd., 2005: 469.
}

98 Robert H. Jackson. Comprendiendo los efectos de las enfermedades del Viejo Mundo...88-133. 
reconstruida muestra las personas desaparecidas en tres cohortes: de 20 a 24 años; de 25 a 29; y 30 a 34. La mayor diferencia fue en el grupo de 25 a $29^{30}$. Los miembros de cada cohorte se habría 9 a 13 años, de 4 a 8, y menores de 4 años, respectivamente, en 1738 en el comienzo de la epidemia de viruela, y habrían estado entre los más susceptibles, los nacidos desde la epidemia de viruela anterior en 1718. La estructura de edad de la población de Corpus Christi mostró menos individuos que faltan en los grupos de mayor edad, y en particular en los grupos de edad nacidos antes de la epidemia de viruela de 1718.

La reducción de San Lorenzo Mártir (Figura 1), que se encuentra al este del río Uruguay, ofrece un caso de estudio de los efectos de la epidemia de viruela. Como ya se ha señalado, la población de la misión experimentó una mortalidad extremadamente pesada en 1739. Los jesuitas establecieron la misión en 1690 mediante la transferencia de guaraníes de Santa María la Mayor, ubicada cerca de la orilla oeste del río Uruguay. En el momento de la transferencia de Santa María la Mayor era una de las más pobladas de las misiones. En 1682, contaba con una población de 5.171 habitantes. Los jesuitas transfirieron 3.512 guaraníes para establecer San Lorenzo. La población de la misión creció durante los próximos treinta años, a un ritmo de entre dos y cinco por ciento al año en los años sin epidemias. En 1732, en vísperas de la primera de las tres epidemias que se propagaron a través de las misiones del Paraguay en la década de 1730, la población de San Lorenzo sumó 6.513.

La primera de las epidemias, en la década de 1730, golpeó a San Lorenzo en 1733. Los jesuitas registraron 771 muertes, y un descenso de un siete por ciento en la población. A finales de 1733, San Lorenzo mantuvo una población de 6.100 guaraníes. La próxima epidemia se extendió a esta misión en 1735, y la población se redujo aún más. Eran 4.548, al final del año, y pasó a 4.405 en 1736. La población se recuperó a 4.814 en 1738, pero luego la viruela estalló en 1739 y diezmó la población. El contagio mató a 1.655 guaraníes clasificados como adultos y 1.025 niños menores de la edad de diez años, es decir más del 55\% de la población. La población se redujo a 974 al final del año 1739.

Figura 1: La población de San Lorenzo, 1690-1827

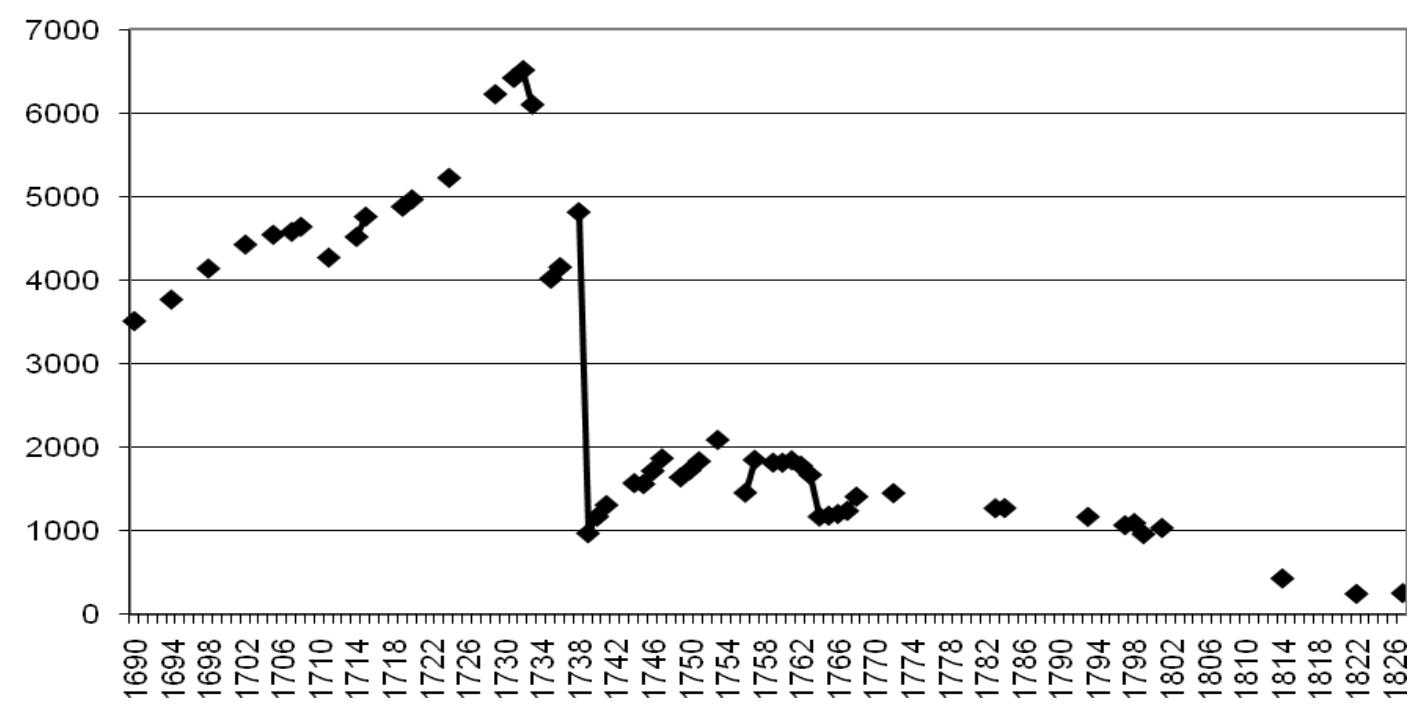

${ }^{30}$ Ibíd., 2004a: 337-366.

99 Robert H. Jackson. Comprendiendo los efectos de las enfermedades del Viejo Mundo...88-133. 


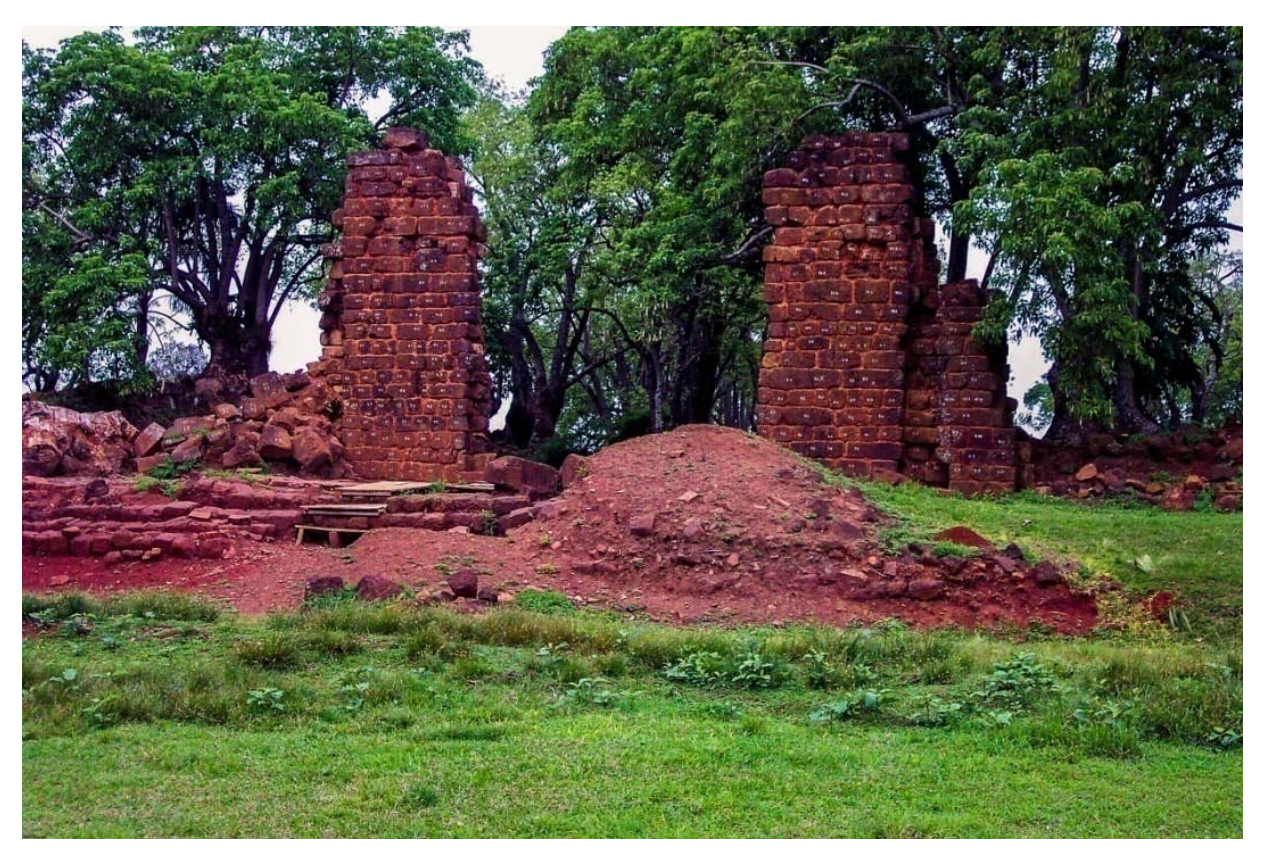

Ilustración 1: Las ruinas de la misión de San Lorenzo Mártir (Rio Grande do Sul, Brasil).

Después de las epidemias, el número de matrimonios registrados en San Lorenzo Mártir aumentó. En 1724 un año no epidémico, la población de San Lorenzo Mártir totalizó 5.224 habitantes. En ese año los jesuitas registraron 52 matrimonios, es decir 10 matrimonios por mil de la población. En la primera epidemia que golpeó a San Lorenzo Mártir en 1733, la población era de 6.100 y el número de matrimonios aumentó a 155 ó 24 por mil de la población. El mismo patrón se produjo a raíz de la epidemia de viruela devastadora de 1738-1740. A finales de 1739, 974 guaraníes se mantuvieron en la misión, y el número de matrimonios fue de 122, ó 25 por mil de población. La misma aumentó a 1.173 en 1740 y 92 matrimonios, ó 95 por cada mil habitantes. Había 1.311 guaraníes en San Lorenzo Mártir en 1741 y los jesuitas registraron 32 matrimonios, ó 27 por mil de población.

\section{La diáspora guaraní (1756-1766) y la epidemia de viruela (1763-1765).}

En 1750, los reyes de España y Portugal firmaron el Tratado de Madrid, que intentó definir las fronteras de Brasil portugués y los territorios españoles en América del Sur. Bajo los términos del Tratado, España cedió el territorio de las siete misiones jesuíticas situadas al este del río Uruguay a Portugal, a cambio de la Colonia del Sacramento, ubicada en el Uruguay moderno. Una cláusula en el Tratado, llamado a la acción militar español-portugués conjunta, debe a los residentes guaraníes de las misiones el resistir la transferencia territorial. El gobierno español dio a los residentes guaraníes de las siete misiones la opción de trasladarse a territorio español, o permanecer bajo el dominio portugués. Los líderes de los clanes guaraníes de las siete misiones optaron por resistir a la transferencia. En 1755, la milicia guaraní de las siete misiones forzó una fuerza militar española a retirarse del territorio de las misiones, pero luego una mayor fuerza español-portugués derrotó a la milicia guaraní en el año siguiente en la batalla de Caibaté.

En 1762, un nuevo rey español anuló unilateralmente el Tratado de Madrid, y ordenó la reocupación del territorio de las misiones al este del río Uruguay. Otra década 
de guerra declarada y no declarada sobrevino mientras que España y Portugal se disputaban la región fronteriza de Río Grande do Sul. En 1777 los dos países firmaron el Tratado de San Ildefonso que definió los límites de Brasil y el territorio español en América del Sur. El territorio de las misiones al este del río Uruguay se mantuvo bajo control español hasta $1801^{31}$.

Censos de las misiones de Paraguay realizados entre 1756 y 1766 documentaron la diáspora guaraní de las siete misiones orientales y la reocupación de las misiones orientales después de 1762. El mayor número de refugiados fueron a esas misiones inmediatamente al oeste del río Uruguay, y el más cercano al territorio transferidos a los portugueses. En 1759, 9.133 de los refugiados vivían en siete misiones en esta área (Concepción, San Francisco Javier, San Carlos, San José, Apóstoles, Los Santos Mártires y Santa María la Mayor) (ver Cuadro 3). En el momento de la reubicación funcionarios reales creían que la transferencia de la población sería permanente. Siempre que fuera posible los jesuitas trasladaron los guaraníes de las misiones orientales a las misiones con las que existían lazos históricos y sociales o familiares, a fin que la afluencia de la nueva población fuera lo menos perjudicial posible. Los jesuitas habían transferido guaraníes de este distrito para establecer varias de las misiones orientales a finales del siglo XVII, y los vínculos sociales y familiares todavía existían.

Un número menor de refugiados fueron reubicados en otras misiones jesuíticas. Un total de 5.133 guaraníes fueron dispuestos en lo que hoy es el sureste de Paraguay (Trinidad, Santos Cosme y Damián, Jesús de Tavarangue, Ytapúa, Santa Rosa, Santiago y Nuestra Señora la Fe). Varias de este grupo de misiones tenían poblaciones relativamente pequeñas, y podrían fácilmente absorber la afluencia de población. En 1759, por ejemplo, Santos Cosme y Damián tenía una población de 1.672 habitantes. En ese momento la misión ocupó un sitio cerca de la orilla oeste del río Paraná, cerca de varias otras misiones (Santiago, Nuestra Señora de Fe, Santa Rosa y San Ignacio Guazú). La afluencia de refugiados de las misiones del este pudo haber sido el factor terminante en la decisión de trasladar Santos Cosme y Damián en 1760 a un nuevo sitio en la misma zona oeste del río Paraná, pero más lejos de otras misiones a fin de evitar cualquier posible conflicto por la tierra con las misiones cercanas ${ }^{32}$. En 1753, la población de las cuatro misiones vecinas ascendió a $13.495^{33}$. En 1765, tras la conclusión formal de la guerra, 2.207 refugiados aun residían en tres misiones, y 2.072 en el año siguiente, cuando la mayoría de los refugiados ya había regresado a los lugares de misión oriental (véase el Cuadro 3).

Dos misiones ubicadas en Corrientes moderna, en la orilla oeste del río Uruguay, acogieron 3.782 refugiados en 1759. La mayoría (3.721) residía en Santo Tomé, ubicada al otro lado del río San Francisco de Borja, una de las misiones del este. Sus residentes guaraníes tenían vínculos históricos, sociales, familiares con los de Santo Tomé. A diferencia de los establecimientos de otras partes del territorio de las misiones, Santo Tomé se encuentra a cierta distancia de las misiones vecinas y por lo tanto no había posibilidad de conflictos por la tierra. En 1759, la población de Santo Tomé fue 3.277, y en ese año hubo 3.721 guaraníes de San Francisco de Borja en la misión que los

\footnotetext{
${ }^{31}$ Para un resumen general al levantamiento guaraní ver Ganson, 2003.

${ }^{32}$ Carbonell de Masy, Blumers y Levinton, 2003.

33 Jackson, 2004c: 129-178.
} 
funcionarios españoles habían trasladado a corta distancia, a través del río Uruguay. Algún guaraní permaneció en el territorio reclamado por Portugal en virtud de los términos del Tratado. En 1759, 3.836 personas vivían en estancias en la antigua tierra de misiones, ahora bajo jurisdicción portuguesa. Estos refugiados fueron al parecer trasladados más tarde a las misiones al oeste del río Uruguay.

Tras la derogación española del Tratado de Madrid, la población guaraní de las siete misiones orientales regresó a sus comunidades. Sin embargo, la reocupación de las misiones orientales llevó varios años, y fue un proceso gradual con la población de las misiones ubicadas más cerca de los asentamientos portugueses (San Juan Bautista, Santo Ángel Custodio, San Luis Gonzaga) ocupado a un ritmo más lento. Tras el cese de las hostilidades durante la Guerra de los Siete Años, España y Portugal lucharon una guerra no declarada por el control de Rio Grande do Sul, que duró una década. En 1766, 3.187 refugiados procedentes de estas dos misiones todavía residían en otras misiones (ver Cuadro 3), y estaban allí cuando se produjo la propagación de la viruela a través de las misiones.

En 1763, el ejército español utilizó las misiones de Paraguay como una base de operaciones para una invasión de asentamientos portugueses en Rio Grande do Sul. Los soldados llevaron la viruela al distrito de la misión. Una grave epidemia se extendió a través de las misiones a fines de 1763, y mató al menos a 12.029 guaraníes en los dos últimos años de la epidemia en 1764 y 1765, como informan los censos que resumían muertes de viruela. El contagio primero estalló en la misión de Santos Cosme y Damián, donde los jesuitas registraron 331 entierros en 1763, o una tasa bruta de mortalidad de 215,6 por mil de población. El contagio había corrido su curso a principios de 1764; el número de muertes en la misión se redujo a 144 en 1764 y 173 en el año siguiente ${ }^{34}$. Después estalló en Santa María la Mayor a finales de 1763, y continuó hasta el año siguiente. En 1763, 316 guaraníes murieron allí, y en 1764 se registraron 712 muertes. La tasa bruta de mortalidad llegó a 123,7 en el primer año y 354,8 en el segundo. A partir de estas dos misiones, la viruela se extendió a casi todos los establecimientos del Paraguay.

Las tasas de mortalidad por viruela diferían entre las misiones. Los jesuitas registran el mayor número de muertes en Santa Rosa en 1764 (1.596), en Loreto en 1765 (1.833), y Los Santos Mártires del Japón en 1764 y 1765 (1.229). La presencia de un gran número de refugiados de las misiones del este y el hacinamiento en las aldeas espacialmente compactos, contribuyó a una fuerte mortalidad en varias misiones, incluyendo a Loreto y Los Santos Mártires del Japón. En 1762, antes de la llegada de las tropas españolas en el distrito de la misión, Loreto y Los Santos Mártires del Japón, respectivamente, tenían una población de 4.708 y 3.225, y acogió 651 y 926 refugiados de las misiones orientales. Por otra parte, ambos se encuentran en áreas con grandes poblaciones guaraníes en misiones vecinas que también albergaban a un gran número de refugiados (véase el Cuadro 3). Las condiciones estaban dadas para un importante brote de viruela en las misiones de Paraguay, con un gran número de los ejércitos potencialmente susceptibles nacidos desde el último foco en la década de 1730, un total de 62.809 niños y adultos jóvenes, de una población de 102.988 reportada en 1762, ó $61 \%$ de la población de las misiones. La presencia de los refugiados y de las operaciones militares en curso en la región, provocaron la epidemia y la mortalidad

\footnotetext{
${ }^{34}$ Ibíd., 2008: 419.
} 
exacerbada en misiones seleccionadas con mayor población, y por lo tanto un mayor número de los ejércitos potencialmente susceptibles.

Como ya se ha señalado, Santa Rosa fue una de las misiones que experimentó una alta mortalidad durante la epidemia (Figura 2). La viruela se extendió a Santa Rosa a finales de 1763, y se volvió especialmente letal en 1764. La epidemia comenzó 23 años después del brote anterior, en 1738-1740. La tasa bruta de natalidad llegó a 69,2, frente a una tasa bruta de mortalidad de 57,1 en 1763, y los entierros totalizaron 228 desde 177 registrados en 1762. En el año siguiente 1.614 nativos murieron, dividiéndose en 1.199 adultos y 415 párvulos. Los censos generales de 1764 y 1765 también registraron el número de muertes atribuidas a la viruela, y el contagio se cobró la vida de 1.596 en Santa Rosa, o el 98,9\% de todas las muertes en el año. La tasa bruta de mortalidad alcanzó 490,3, que fue una de las más altas registradas en las misiones de Paraguay. La población disminuyó a 1.934 a finales de 1765 (véase el Cuadro 5).

Figura 2: La población de Santa Rosa, 1702-1803

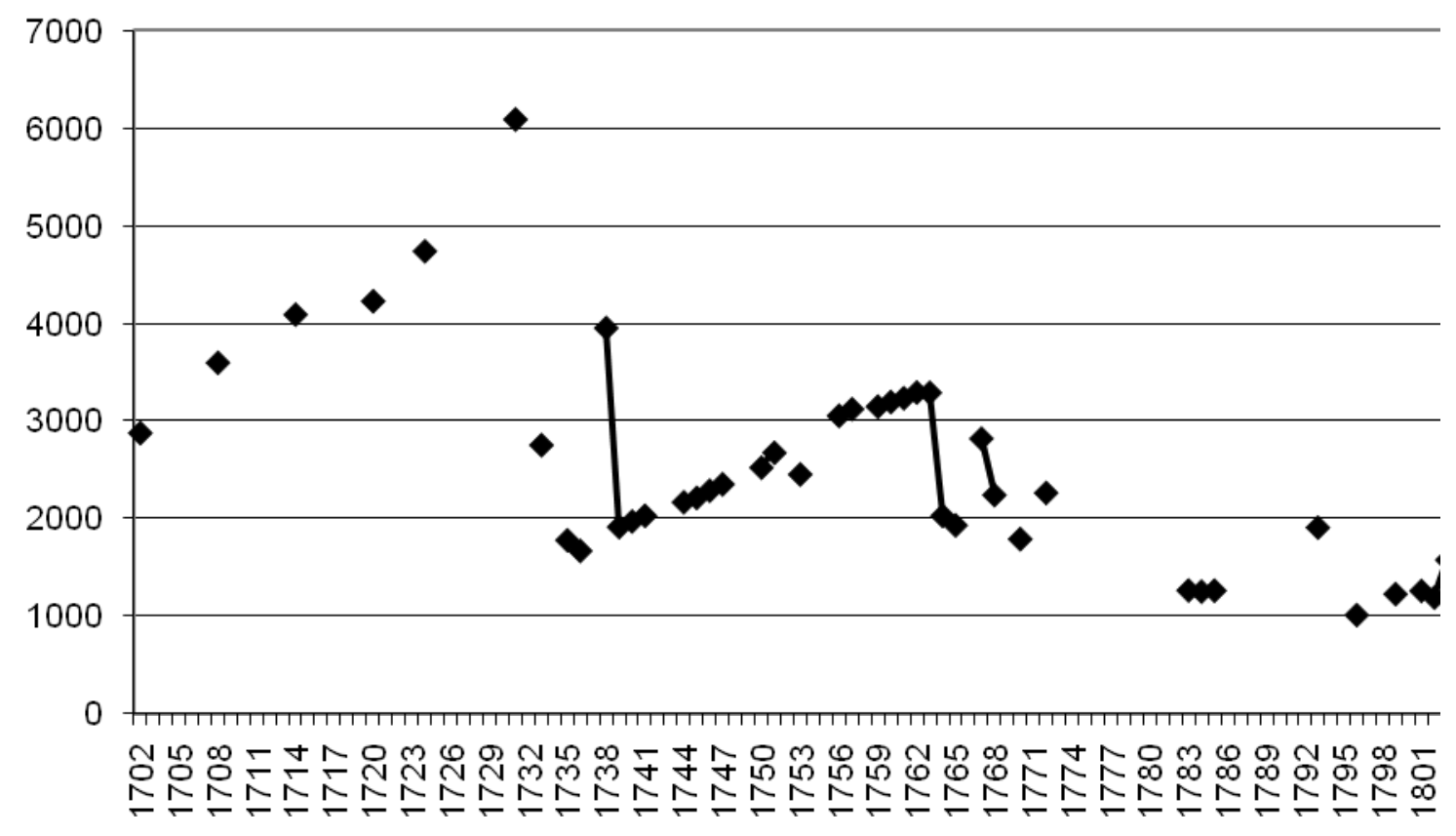

La población de Santa Rosa se recuperó lentamente después de la devastadora epidemia de viruela, y siguió creciendo en los años inmediatamente después de la expulsión de los jesuitas y su sustitución por los franciscanos. La evidencia muestra un aumento en el número de matrimonios después de la epidemia de viruela. En 1763, los jesuitas registraron 31 matrimonios en Santa Rosa, ó 14 por mil de la población. Esto aumentó a 70 en 1764 y 238 el año siguiente, en 1765, o el 31 y 11 por mil de la población, respectivamente. En 1767, la población era de 2.243 habitantes.

\section{El holocausto en Yapeyú, 1770-1772.}

Los jesuitas establecieron Los Santos Reyes de Yapeyú, a orillas del río Uruguay en 1627. En el transcurso del siglo XVII, la población de Yapeyú se estancó, y se experimentaron bajas tasas de crecimiento. En 1647, la población era de 1.600, y ésta 
creció a lo largo de los próximos conciertos de décadas, a 2.477 en 1682. Los números se redujeron a 1.865 en 1691, muy probablemente como consecuencia de una epidemia. La población de Yapeyú fue de 4.360 en 1724 a raíz de la reubicación de familias de San Francisco Xavier, y aumentó a 5.666 en 1731.

Las epidemias diezmaron las poblaciones de la mayoría de las misiones del Paraguay en la década de 1730 y de nuevo en 1764-1765. Sin embargo, las epidemias no redujeron significativamente la población de la misión de Yapeyú. En 1733, por ejemplo, la tasa bruta de mortalidad por mil fue 126,8 o un poco más del $12 \%$ de la población, pero estaba dentro de lo normal (no epidémica), variando durante el resto de la década. La población de Yapeyú se redujo a 5.106 en 1735, pero luego creció y llegó a 5.410 en 1738; 5.713 en 1739; 5.687 en 1740 y 5.748 en 1741. Por el contrario, la mortalidad en la cercana La Cruz fue mucho mayor. En 1733, por ejemplo, la tasa bruta de mortalidad fue de 174,5 por mil habitantes, y 416,6 por mil durante el brote de viruela en 1739.

La mortalidad en Yapeyú (Figura 3) también fue baja durante la epidemia de viruela de 1764-1765 (en ambos años las tasas de natalidad fueron más altas que las tasas de mortalidad), lo que sugiere que los jesuitas instituyeron medidas de cuarentena bastante eficaces para aislar a la misión o prevenir que los individuos ya infectados entren en contacto con la población general. Como fue el caso durante la epidemia en la década de 1730, la viruela mató a más personas en la cercana misión de La Cruz. La viruela mató a 571 personas allí en 1765, y la tasa bruta de mortalidad fue 199,6 por mil, mucho más alto que en Yapeyú. La población de Yapeyú siguió creciendo en la década de 1740, 1750, y 1760, y llegó a 6.147 en 1745; 7.418 en 1759; 7.458 en 1763; 7.974 en 1767 y 8.510 en 1768, el año de la expulsión de los jesuitas. Yapeyú fue la más poblada de las misiones de Paraguay al final del período jesuítico.

Cuando se produjo la propagación de la viruela en Yapeyú entre 1770 y 1772, las tasas de mortalidad eran extremadamente altas. La nueva administración civil no respondió con la mayor eficacia al brote, y más de 5.000 guaraníes habrían muerto ${ }^{35}$. La tasa bruta de mortalidad fue de más de 600 por mil, haciendo de ésta, la epidemia documentada más letal de las misiones del Paraguay. La alta mortalidad puede atribuirse a la gran cantidad de personas potencialmente sensibles nacidos desde el último brote grave en la década de 1730. En otras palabras, la población de la misión era extremadamente vulnerable a la viruela en 1770. La población de Yapeyú se redujo de 8.510 reportados en 1768, a 3.322, cuatro años después. La expulsión de los jesuitas en 1768, aumentó los movimientos de personal militar en la región, en relación con el conflicto en curso con los portugueses sobre las tierras fronterizas en disputa en Río Grande do Sul, y un crecimiento del comercio regional facilitó la propagación de enfermedades epidémicas.

Un padrón de tributarios detallado preparado en 1771 documentó los efectos de la alta mortalidad de la viruela en la población (véase el cuadro 6). Como se señaló anteriormente, la viruela cobró particularmente una gran mortalidad entre los niños y adultos nacidos después de 1740 . Por otra parte, a raíz de la epidemia, se mantuvieron pocas familias numerosas, y la mayoría estaban constituidas por matrimonio sin hijos (39 \%) o uno o dos hijos (46 \%). Hubo menos familias numerosas con tres o más hijos

\footnotetext{
35 Yapeyú, 1771, Padrón de Nuestra Señora de los Reyes de Yapeyú, Archivo General de la Nación, Buenos Aires, Sala 9-18-8-7.
} 
(15 \%) que antes del estallido de contagio. Hubo un marcado incremento en el número de viudas que habían perdido a su cónyuge, y no se habían vuelto a casar. El censo enumeró 278 viudos y 101 viudas. El censo también registró 840 niños huérfanos ${ }^{36}$. Al mismo tiempo, la evidencia también documenta un rebote o recuperación en números totales. La población creció a 4.747 en 1783 y 5.170 en $1793^{37}$.

Figura 3: La población de Yapeyú, 1541-1802

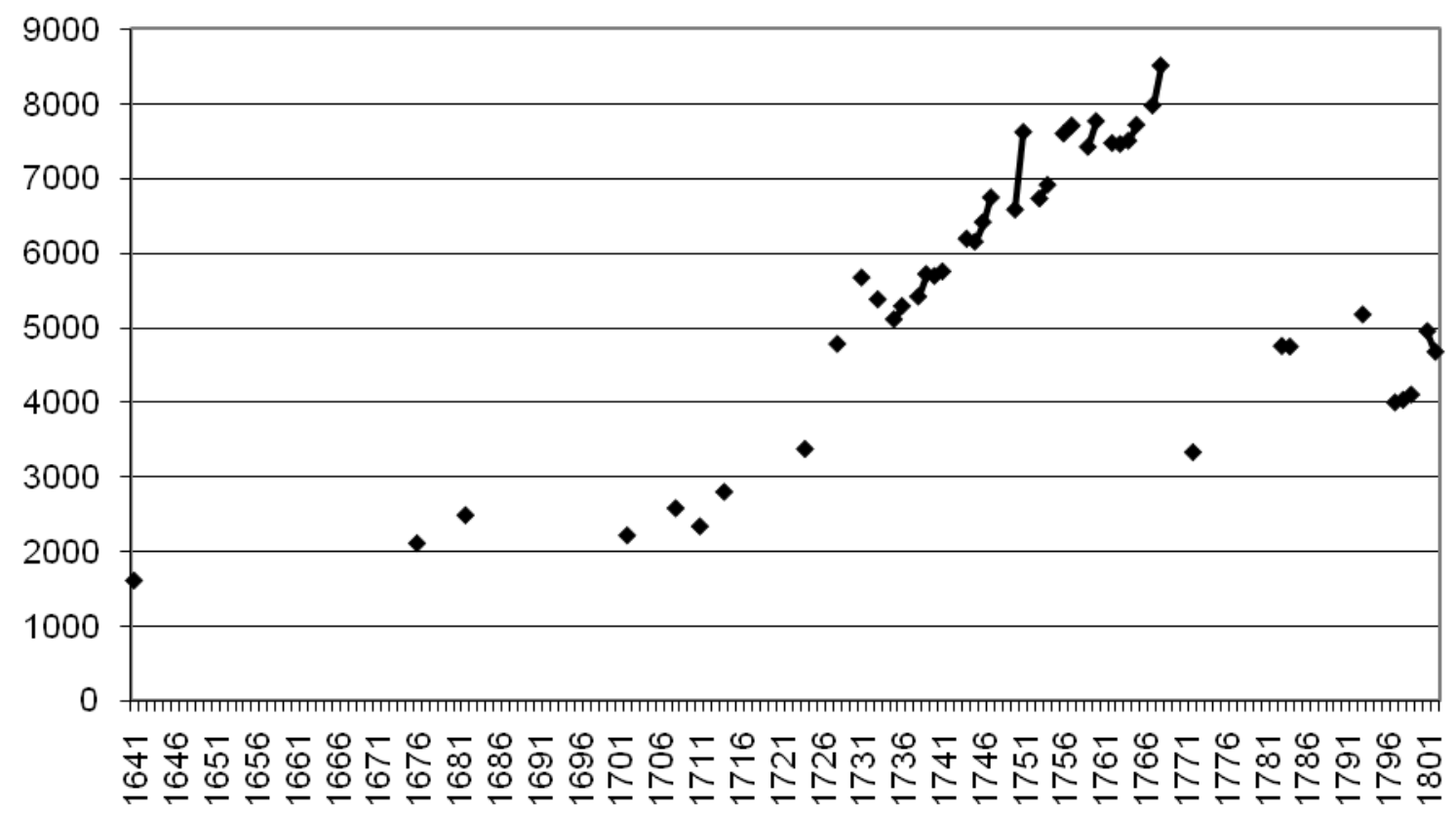

¿Cuáles fueron los efectos a corto y largo plazo de las epidemias en las poblaciones de las misiones del Paraguay? La siguiente sección resume los patrones demográficos en la misión de San Nicolás, situada en lo que hoy es el estado brasileño de Río Grande do Sul. San Nicolás fue uno de las más pobladas de las misiones de Paraguay, y experimentó crisis de mortalidad graves.

\section{Las tasas vitales de las misiones del Paraguay: el caso de San Nicolás.}

Los jesuitas establecieron San Nicolás en 1626 en un sitio cerca de la orilla oriental del río Uruguay, pero más tarde se trasladaron a la misión al oeste del río, después de los ataques de los bandeirantes de la década de 1630. Los jesuitas unieron a San Nicolás a Apóstoles, a pesar de que se registró la población de San Nicolás por separado en los censos. Aunque en el mismo lugar, las dos misiones permanecieron separadas en términos de contabilidad y administración. En 1687, los jesuitas trasladaron San Nicolás a un nuevo emplazamiento al este del río Uruguay, con la

\footnotetext{
${ }^{36}$ Ibíd.

${ }^{37}$ Ver, por ejemplo, Vicente Ximénez, Villa de Concepción, abril 26, 1790, Lista de los Yndios Guaranis procedentes de los Pueblos de Misiones que se hallan en las Villas de Concepción del Uruguay, San Joséph de Gualeguayes y San Antonio del Gualeguay, y sus partidos, Archivo General de la Nación, Buenos Aires, Sala 9-17-3-6.
} 
población de la misma comunidad y de Apóstoles ${ }^{38}$. Los jesuitas reubicaron a San Nicolás después que los portuguesas establecieron a Colonia del Sacramento en 1680, en un esfuerzo por afirmar la soberanía española sobre las tierras fronterizas en disputa. En 1690, 3.648 guaraníes vivían en el nuevo sitio de la misión.

La población de San Nicolás creció durante los siguientes 40 años, principalmente como resultado de las tasas de natalidad que eran generalmente más altas que las tasas de mortalidad. En 1698, por ejemplo, la población creció en casi un 2 $\%$, y en alrededor de un $3 \%$ en 1700. Al mismo tiempo, las epidemias periódicas estancaron el crecimiento demográfico. La epidemia de viruela en 1718 redujo la población de San Nicolás, que pasó de 6.658 en 1715 a 5.729 en 1719. Sin embargo, la población se recuperó o se recupera después de la epidemia, y alcanzó un máximo registrado de 7.751 en 1732 (véase Cuadro 7).

Las epidemias en la década de 1730 redujeron la población de San Nicolás de nuevo, y el brote de viruela de 1738-1740 fue especialmente grave en la misión. En los años 1735 a 1740, la población se redujo de casi 5.000 a 2.194 en el último año. Casi el $10 \%$ de los residentes de la misión murieron durante los dos primeros brotes en 1733 y 1735, pero la mayor disminución se produjo en 1739. El censo general preparado en ese año registró la muerte de 1.030 adultos y 645 párvulos. La población se redujo de 5.071, registrado al cierre de 1738, a 2.048 a finales de octubre de 1739, y además se llegó a 1.772 a finales de diciembre del mismo año. Este descenso se debió a una fuerte mortalidad durante el brote, pero también la huída de algún guaraní que lo hiciera para escapar de la temida enfermedad.

La población se recuperó después de la epidemia, pero no regresó a los niveles de población registrada al comienzo de la década. Hubo un mayor número de matrimonios después de la misma. En 1733, cuando la población ascendía a 7.415, los jesuitas registraron 179 matrimonios y 124 matrimonios en 1740 con una población reducida a menos de 2.000. En el primer año los jesuitas registraron 23 matrimonios por cada mil habitantes, y el 70 por mil de habitantes en 1740. El número de matrimonios se redujo a 58 en 1741, ó 26 matrimonios por cada mil habitantes.

La próxima crisis se produjo en 1755 y 1756 con la aplicación del Tratado de Madrid (1750) y el levantamiento guaraní. El censo de 1756 registró solo 416 guaraníes todavía en la misión, y el resto de la población ya se había dispersado. El censo de 1759 reportó 1.548 guaraníes en una de las estancias de la misión, y los funcionarios reales ordenaron el traslado del resto de la población a otras misiones incluyendo a Jesús, Trinidad, La Cruz, Santa Rosa, Guazú y Apóstoles. Esta última albergaba 1.357 de los fugitivos, que tenían sentido dada la conexión histórica entre las poblaciones de las dos misiones. En el momento de la reubicación, funcionarios reales creían que la transferencia de la población sería permanente. Tras la derogación unilateral de España del Tratado de Madrid y la reocupación del territorio de las misiones, los guaraníes regresaron a San Nicolás. En 1763, 4.123 estaban allí, y solo 37 se mantuvieron en otras misiones.

${ }^{38}$ Maeder, 1996: 44-51. 


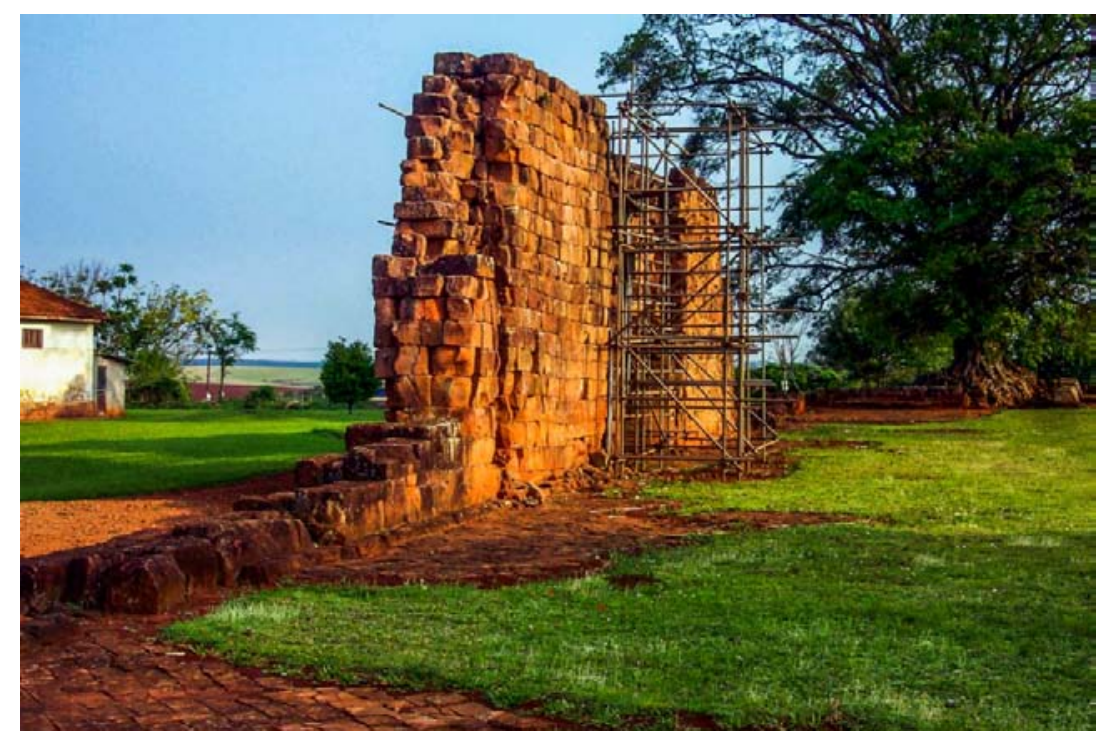

Ilustración 2: Las ruinas de la misión de San Nicolás (Rio Grande do Sul, Brasil).

En 1764 la epidemia de viruela mató a 341 habitantes de San Nicolás, alrededor del $12 \%$ de la población. A raíz de la epidemia de la población se sitúa en 3.925, y el número aumentó ligeramente a 4.194 en 1768, en el momento de la expulsión de los jesuitas. Administradores civiles y misioneros dominicos reemplazaron a los jesuitas en San Nicolás. Aunque el guaraní no se resistió a la eliminación de los jesuitas como los funcionarios reales habían temido, la expulsión y el cambio en la administración contribuyeron a un aumento de la emigración y la disminución de la población que vivía en la misión ${ }^{39}$. El hecho que los guaraníes no se resistieran a la expulsión, no significa que los residentes de la misión no tuvieron problemas con la nueva administración, y las fricciones resultantes del cambio contribuyeron a la emigración ${ }^{40}$. En 1772, la población de la misión era de 3.471, y de 2.406, treinta años más tarde.

Precisamente en 1801, una milicia portuguesa ocupó las siete misiones orientales, y el territorio al este del río Uruguay se convirtió en una parte permanente de Brasil. La emigración se aceleró tras la ocupación portuguesa de las siete misiones, y el gobierno colonial promovió asentamientos no guaraníes en la región a través de la oferta de concesiones de tierras, con el fin de asegurar su control sobre el territorio. En 1814, 1.545 guaraníes aún vivían en San Nicolás, pero este número se redujo a 404 en 1827.

No todas las misiones administradas por los jesuitas en la Provincia del Paraguay evidenciaron las mismas crisis de mortalidad graves como se discutió anteriormente para las misiones del Paraguay. En la siguiente sección se analizan los patrones demográficos en las misiones de Tarima y en la región del Chaco. Estos estudios de caso comparativos, también ofrecen la oportunidad de contrastar las poblaciones de agricultores sedentarios y nómadas cazadores y recolectores. Por otra parte, los estudios de casos son, por ejemplo de las misiones del Tarima, de poblaciones que no están conectadas a las redes comerciales regionales de transporte fluvial. El aislamiento geográfico podría proteger a las comunidades de la mortalidad epidémica.

\footnotetext{
${ }^{39}$ Wilde, 1999: 141-172.

${ }^{40}$ Hernández, 1999: 83-100.
} 


\section{Las tasas vitales de las misiones de la región de Tarima y Chaco.}

En el período de expansión inicial de la frontera jesuita en Paraguay desde 1610, los jesuitas establecieron misiones al norte y al noreste de Asunción, en una región conocida como Itatín, en lo que hoy es el norte de Paraguay y parte de Mato Grosso en Brasil $^{41}$. Los jesuitas más tarde abandonaron las misiones del Itatín frente a las incursiones de los bandeirantes, y se trasladaron a las poblaciones de estas misiones, a lo que hoy es el sureste de Paraguay.

En la década de 1740, los jesuitas establecieron dos nuevas misiones al noreste de Asunción. Fundaron la primera, llamada de San Joaquín en 1746, y el segundo llamado San Estanislao en $1749^{42}$. El Cuadro 8 resume las tasas vitales de las dos misiones en años seleccionados. Los jesuitas registraron las tasas vitales de las dos misiones en los censos generales de las misiones del Paraguay, aunque el censo de 1764 omitió información sobre San Joaquín y San Estanislao. Como fue el caso en las comunidades del Paraguay, estas últimas poblaciones eran de altas tasas de fecundidad y de alta mortalidad. Por otra parte, la evidencia sugiere que los jesuitas siguieron reclutando cientos de los no cristianos a asentarse en las misiones, particularmente San Estanislao. El número de bautismos allí registrados fue mayor de lo esperado de las tasas de natalidad normales, incluso a partir de una población de alta fertilidad. La población de San Estanislao casi se duplicó entre 1759 y 1766, pasando de 1.090 registrados en 1759 a 1.930 en 1766 . Las tasas vitales y el tamaño de la población de San Joaquín sugieren un patrón similar, aunque no con un crecimiento tan rápido de la población. El número de indígenas que vivían en San Joaquín pasó de 1.280 en 1759 a 1.755 en 1765, pero luego se redujo a 1.440 en el año siguiente, tal vez debido a la mortalidad epidémica.

San Estanislao y San Joaquín fueron localizados cerca de Asunción, uno de los mayores asentamientos españoles en la región. Las epidemias se propagaron a las dos misiones con la misma frecuencia que a las misiones del Paraguay. Aunque no hay información para 1764, los datos de 1763 y 1765 documentan el brote de viruela en las dos misiones, al mismo tiempo que el brote en las misiones del Paraguay. Sin embargo, la mortalidad fue menor. La TBM en San Joaquín era 85,0 en 1765. A raíz de la expulsión de los jesuitas de San Joaquín y San Estanislao, continuaron existiendo como comunidades estables. Es probable que hubiera una emigración de las dos misiones, pero las dos ex-misiones evolucionaron hasta convertirse en comunidades multiétnicas (ver Cuadro 8).

La segunda comparación se hace con un grupo de misiones establecidas entre las poblaciones nómadas de cazadores y recolectores de la región del Chaco. Las misiones operadas por períodos cortos de tiempo ${ }^{43}$. Los jesuitas fueron incapaces de convencer a los grupos indígenas nómadas a establecerse de forma permanente en las misiones, y cambiar su estilo de vida para convertirse en agricultores sedentarios. Una de las razones de este fracaso más probable fue la falta de voluntad de los hombres a participar en el trabajo agrícola sostenido, que era similar a la recogida de alimentos de plantas

\footnotetext{
${ }^{41}$ Maeder, 1996: 17-22.

42 Ibid., 52-54; Ganson, 2003: 48.

43 Saeger, 2000.
} 
silvestres, que fue el género de trabajo para las mujeres. Los hombres obtuvieron estatus de sus habilidades como cazadores y guerreros, y en su etnos haciendo trabajos que asociaban como trabajos de la mujer, habría sido humillante. La misión Chaco examinada aquí es San Fernando de Abipones, elegida porque un censo elaborado en 1762 registró bautismos y entierros durante casi una década, y se incluye información detallada sobre las tendencias demográficas.

Los jesuitas establecieron San Fernando de abipones en 1750 en la orilla occidental del Río Paraná, frente a Corrientes. Tras la expulsión de los jesuitas, los franciscanos administraron la misión hasta el inicio del movimiento de independencia en la región del Río de la Plata, y en ese momento los abipones reanudaron asaltar establecimientos españoles como lo habían hecho antes del establecimiento de la misión. Los misioneros abandonaron la misma, terminando así el esfuerzo de evangelizar a los grupos nómadas del Chaco ${ }^{44}$. San Fernando fue una de las cuatro misiones de los jesuitas establecidas para abipones a finales de los años 1740 y principios de 1750. Las otras eran San Jerónimo, Concepción y San Carlos ${ }^{45}$.

Los patrones demográficos en San Fernando de abipones eran diferentes de las misiones del Paraguay y Chiquitos (ver Cuadros 9 y 10). Los jesuitas bautizaban principalmente a los niños, y a muy pocos adultos. Aquellos adultos que aceptaron el bautismo lo hicieron solo en el momento de la muerte. Los jesuitas no lograron convencer a la mayoría de los adultos a aceptar el bautismo, lo que hubiera significado un cambio radical en su forma de vida. La evidencia del censo de 1762 indica que los abipones permitieron a sus hijos ser bautizados, siendo la única condición que los jesuitas podían exigir a cambio de la admisión a la comunidad de misión para los que se quedaron, aunque solamente sea por períodos cortos. Pocos abipones fueron enterrados en la misión, y muchos adultos probablemente murieron lejos de la misma ${ }^{46}$. Las pruebas contenidas en el censo de 1762 muestran que la mayoría de los adultos rechazaron la nueva fe. Un análisis de la estructura por edad y sexo de San Fernando de abipones muestra que las mujeres y los niños constituyen la mayoría de la población, y los hombres abipones optaron por no residir en la misión. Esto sugiere que el abipón utilizó la misión como un lugar de refugio para dejar a sus mujeres y niños cuando fueron a cazar, o hacer la guerra contra los grupos nativos rivales.

Varios informes también enumeran la población de San Jerónimo, aunque no con el mismo detalle que en el informe de 1762 en San Fernando. En 1758, los jesuitas dividen la población de la misión entre los "cristianos" (los ya bautizados) y los que siguen recibiendo formación religiosa antes de ser bautizados. La población del primer grupo ascendió a 341 divididos entre 56 familias. El segundo grupo ascendió a 250 divididos entre 74 familias. La población total de la misión era de $591^{47}$. La Carta Anua de 1762 también dividió la población entre los ya bautizados y los que recibían instrucción religiosa. El primer grupo ascendió a 363 personas divididas en 55 familias, y el segundo grupo de 207 en 65 familias. Durante 1761, los jesuitas bautizaron cinco

\footnotetext{
${ }^{44}$ Ibid., 30, 38-39, 166-167.

45 Page, 2012: 323-340.

${ }^{46}$ Un patrón similar se observa en las misiones franciscanas que se establecen entre los grupos nómadas en Texas conocidos colectivamente como los Karankawas (Jackson, 2001: 7-40 y Jackson, 2004d: 31-50.

47 Estado de La Reducción de San Gerónimo de Abipones, En el Año 1758. Archivo General de la Nación, Buenos Aires, Sala 9-10-6-10.
} 
adultos y 29 niños. Cinco murieron sin recibir la extremaunción, y ocho niños y dos adultos recibieron un entierro en la iglesia. El censo también enumeró nueve categorizados como cautivos (cautivos y cautivas) ${ }^{48}$. La viruela se extendió también a las misiones del Chaco, pero los informes existentes sobre San Fernando y San Jerónimo no proporcionan información sobre la mortalidad. Fuentes cualitativas reportan las reacciones de los indígenas a los brotes de viruela. Huirse de las misiones era una respuesta común también documentada en otras misiones fronterizas, pero esta respuesta también contribuyó a la propagación del contagio ${ }^{49}$.

\section{Conclusiones.}

Durante los siglos XVII y XVIII la viruela mató a miles de guaraníes, y en casos extremos la mortalidad alcanzó 50 ó 60 \% de la población. Las altas tasas de mortalidad aproximaban a niveles postulados para las epidemias "virgin soil" del siglo XVI, y está cerca de 200 años después de la colonización española inicial en la región. Al mismo tiempo, hubo una variación considerable en las tasas de mortalidad entre las comunidades de misión, y entre grupos de misiones y diferentes poblaciones en la región más grande del Río de la Plata. Mientras que algunas comunidades misioneras experimentaron mortalidad catastrófica, otras no lo hicieron. A raíz de las crisis de mortalidad graves, las poblaciones de las misiones fueron recuperadas a través de la formación de nuevas familias y las altas tasas de natalidad.

Las epidemias se produjeron alrededor de una vez por cada generación, o alrededor de cada 20 años. La mortalidad en las misiones del Paraguay fue más alta entre los niños y los adolescentes, o en otras palabras, los individuos nacidos desde el brote anterior. Esto desafía la noción de que las poblaciones indígenas crecían inmunes con el tiempo. Más bien, los que sobrevivieron al contagio tenían inmunidades y muy probablemente sobrevivirían si se infectaban nuevamente; mientras que los nacidos después de un brote anterior serían más susceptibles. Varios factores contribuyeron a la alta mortalidad epidémica. Uno era el gran tamaño de las poblaciones de la misión que vivieron codo a codo en las comunidades nucleadas. Las poblaciones guaraníes tenían altas tasas de natalidad y un gran número de niños que serían aptos al contagio. Por último, dicho contagio se extendió fácil y rápidamente a lo largo de los ríos. Otras poblaciones con diferentes estructuras demográficas y que comunicaban con otras comunidades por tierra, a menudo sufrieron menores tasas de mortalidad durante las epidemias.

¿Qué implicaciones tiene el análisis de la mortalidad epidémica documentada, cuando se considera el modelo de las epidemias "virgin soil" en el siglo XVI, y de la interpretación de una disminución de la población continua durante más de un siglo? Epidemias bien documentadas ponen en duda los supuestos básicos del modelo, y los defensores de esta interpretación no han presentado argumentos convincentes en apoyo de la idea, con respecto a que las epidemias del siglo XVI eran diferentes de brotes posteriores. A la luz de los resultados de las epidemias de viruela del siglo XVIII en las misiones del Paraguay, el modelo para el cambio demográfico del siglo XVI requiere ser modificado.

\footnotetext{
${ }^{48}$ Anua de la Reducción de San Gerónimo de Abipones, desde 1 de Enero de 1761 hasta 1 del mismo mes de 1762, Archivo General de la Nación, Buenos Aires, Sala 9-10-6-10.

${ }^{49}$ Rosso, 2011: 17-18.
}

110 Robert H. Jackson. Comprendiendo los efectos de las enfermedades del Viejo Mundo...88-133. 


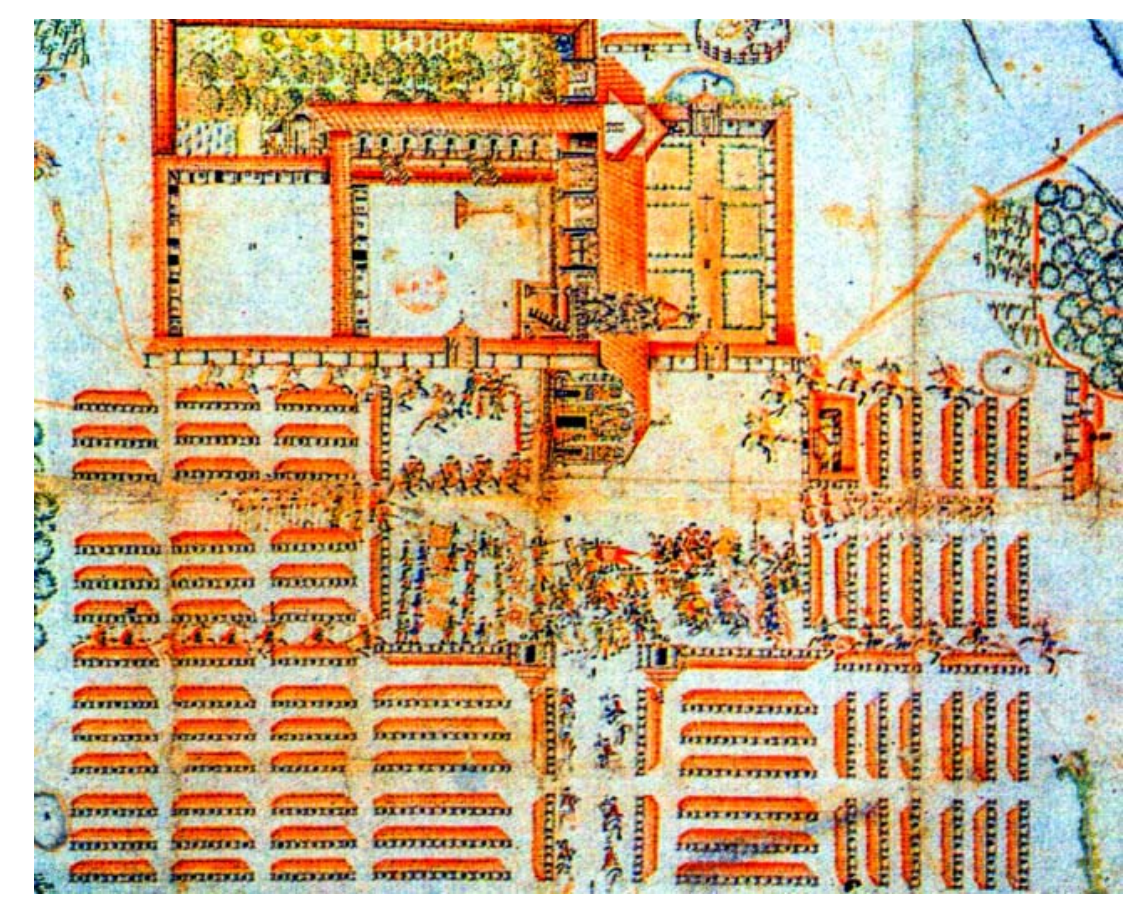

Figura 4: Detalle del mapa de San Juan Bautista, misión que muestra el alojamiento nativo. Los guaraníes vivían en estructuras con varios apartamentos. Este arreglo de vivienda facilitó la propagación del contagio. Plano de San Juan Bautista, Archivo de Simancas, Estado 7381-71.

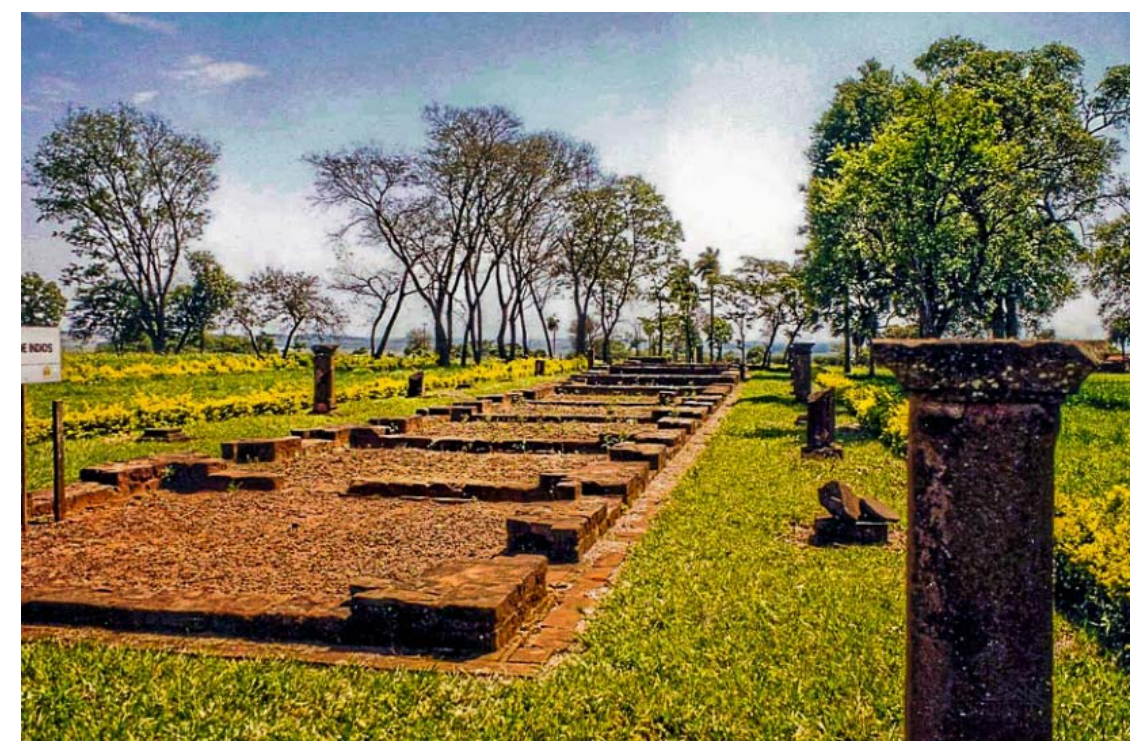

Figura 5: Ruinas de las viviendas de los nativos, Jesús de Tavarangue. 


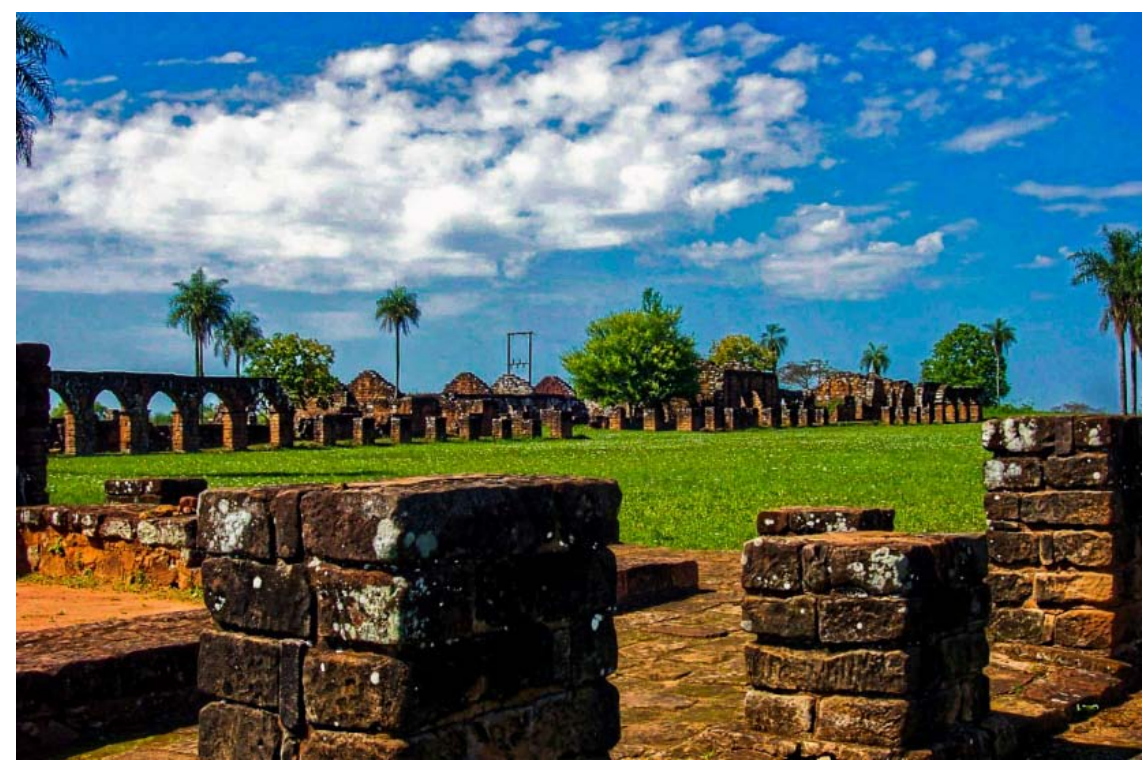

Figure 6: Ruinas de las viviendas de los nativos, Trinidad.

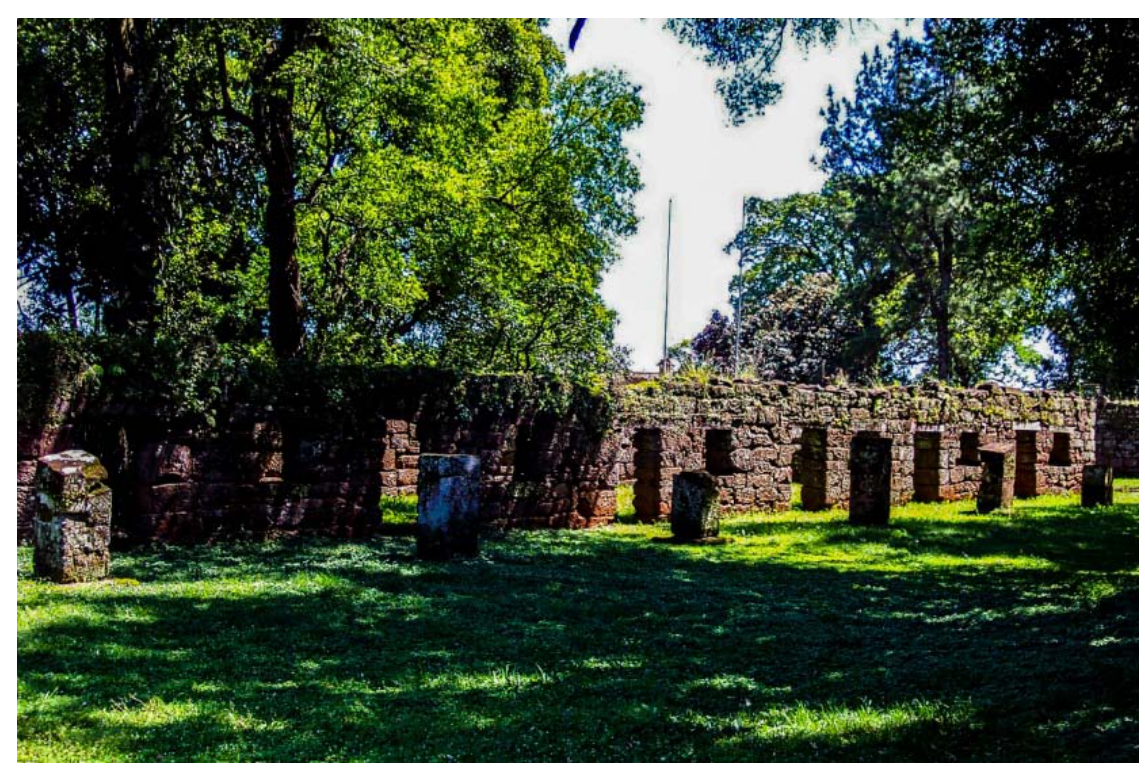

Figure7: Ruinas de las viviendas de los nativos, San Ignacio Miní.

Cuadro 1: Entierros y tasas brutas de mortalidad en las misiones de Paraguay en 1733 y 1736.

\begin{tabular}{|c|c|c|c|c|c|c|}
\hline & \multicolumn{2}{|c|}{1733} & \multicolumn{2}{c|}{1736} & \multicolumn{2}{c|}{$\begin{array}{c}\text { Tasa Bruta de } \\
\text { Mortalidad/1000 }\end{array}$} \\
\hline Misión & Adultos & Párvulos & Adultos & Párvulos & $1733 \#$ & $1736 \#$ \\
\hline Guazú & 560 & 632 & 50 & 40 & 509.0 & 57.3 \\
\hline La Fe & 1365 & 1253 & 58 & 13 & 389.4 & 27.9 \\
\hline Sta. Rosa & 900 & 1363 & 43 & 37 & 459.2 & 48.4 \\
\hline Santiago & 76 & 131 & 58 & 61 & 98.3 & 44.0 \\
\hline Ytapúa & 243 & 568 & 89 & 102 & 115.9 & 41.3 \\
\hline
\end{tabular}

112 Robert H. Jackson. Comprendiendo los efectos de las enfermedades del Viejo Mundo...88-133. 
IHS. Antiguos jesuitas en Iberoamérica ISSN: 2314-3908

\begin{tabular}{|c|c|c|c|c|c|c|}
\hline & \multicolumn{2}{|c|}{1733} & \multicolumn{2}{|c|}{1736} & \multicolumn{2}{|c|}{$\begin{array}{c}\text { Tasa Bruta de } \\
\text { Mortalidad/1000 }\end{array}$} \\
\hline Misión & Adultos & Párvulos & Adultos & Párvulos & 1733\# & $1736 \#$ \\
\hline Cand. & 52 & 194 & 49 & 101 & 24.3 & 52.1 \\
\hline San Cosme & 80 & 182 & 117 & 99 & 112.1 & 128.2 \\
\hline Sta. Ana & 377 & 471 & 151 & 174 & 189.5 & 76.6 \\
\hline Loreto & 515 & 471 & 779 & 542 & 145.0 & 423.5 \\
\hline San Ignacio & 192 & 257 & 275 & 236 & 59.6 & 227.6 \\
\hline Corpus & 324 & 261 & 161 & 95 & 89.6 & 108.1 \\
\hline Trinidad & 138 & 204 & 68 & 64 & 89.2 & 74.1 \\
\hline Jesús & 136 & 154 & 66 & 64 & 84.4 & 58.4 \\
\hline San Carlos & 44 & 201 & 68 & 111 & 70.8 & 55.2 \\
\hline San José & 117 & 249 & 167 & 125 & 96.2 & 82.5 \\
\hline Apóstoles & 149 & 178 & 92 & 69 & 60.7 & 44.1 \\
\hline Concep. & 102 & 229 & 90 & 190 & 55.5 & 43.4 \\
\hline Mártires & 154 & 337 & 72 & 127 & 124.5 & 58.4 \\
\hline La Mayor & 223 & 298 & 133 & 132 & 133.3 & 110.4 \\
\hline San Javier & 172 & 289 & 166 & 163 & 115.5 & 107.7 \\
\hline San Nicolás & 204 & 595 & 362 & 364 & 103.5 & 110.0 \\
\hline San Luis & 218 & 718 & 163 & 138 & 148.9 & 66.1 \\
\hline San Lor. & 400 & 371 & 119 & 140 & 117.0 & 57.7 \\
\hline San Miguel & 240 & 296 & 50 & 80 & 110.6 & 31.9 \\
\hline San Juan & 226 & 272 & 49 & 152 & 96.6 & 39.2 \\
\hline Stos. Áng & 129 & 207 & 117 & 102 & 66.3 & 50.3 \\
\hline Sto. Tomé & 60 & 140 & 54 & 71 & 57.5 & 39.0 \\
\hline San Borja & 124 & 235 & 97 & 79 & 115.6 & 33.6 \\
\hline La Cruz & 246 & 617 & 77 & 129 & 174.5 & 46.0 \\
\hline Yapeyú & 174 & 559 & 38 & 169 & 129.0 & 40.9 \\
\hline
\end{tabular}

\# Estimado.

Fuente: Enumeratio Annua, 1733, Archivo General de la Nación, Buenos Aires, Sala 9-6-9-6; Enumeratio Annua, 1736, Archivo General de la Nación, Buenos Aires, Sala 9-6-9-7; Catálogo de la numeración annual de las Doctrinas del Río Paraná Año 1736, Archivo General de la Nación, Buenos Aires, Sala 9-6-9-7; Pablo Hernández, S.J., Organización social de las Doctrinas Guaraníes de la Compañía de Jesús, 2 vols. (Barcelona: Gustavo Gili Editor, 1913) 2: 616-617.

Cuadro 2: Entierros y tasas brutas de mortalidad en las misiones de Paraguay 1738-1740.

\begin{tabular}{|c|c|c|c|c|c|c|c|c|c|}
\hline & \multicolumn{2}{|c|}{1738} & \multicolumn{2}{c|}{1739} & \multicolumn{2}{c|}{1740} & \multicolumn{3}{c|}{$\begin{array}{c}\text { Tasa Bruta de } \\
\text { Mortalidad/1000 }\end{array}$} \\
\hline Misión & Adultos & Parvulos & Adultos & Párvulos & Adultos & Párvulos & $1738 \#$ & 1739 & 1740 \\
\hline Guazú & & & 22 & 66 & 27 & 84 & & 47.7 & 56.5 \\
\hline La Fe & & & 46 & 98 & 36 & 83 & & 53.3 & 41.0 \\
\hline
\end{tabular}

113 Robert H. Jackson. Comprendiendo los efectos de las enfermedades del Viejo Mundo...88-133. 


\begin{tabular}{|c|c|c|c|c|c|c|c|c|c|}
\hline \multirow{2}{*}{} & \multicolumn{2}{|c|}{1738} & \multicolumn{2}{c|}{1739} & \multicolumn{2}{c|}{1740} & \multicolumn{3}{c|}{$\begin{array}{c}\text { Tasa Bruta de } \\
\text { Mortalidad/1000 }\end{array}$} \\
\hline Misión & Adultos & Parvulos & Adultos & Párvulos & Adultos & Párvulos & $1738 \#$ & 1739 & 1740 \\
\hline Sta. Rosa & & & 26 & 56 & 30 & 64 & & 44.9 & 49.1 \\
\hline Santiago & & & 38 & 57 & 37 & 55 & & 22.8 & 22.5 \\
\hline Ytapúa & & & 98 & 164 & 18 & 31 & & 97.4 & 18.9 \\
\hline Cand. & 1.163 & 365 & 13 & 66 & 10 & 70 & 496.0 & 52.3 & 53.2 \\
\hline San Cosme & 220 & 98 & 32 & 14 & 5 & 14 & 205.7 & 37.6 & 15.4 \\
\hline Sta. Ana & & & 35 & 89 & 31 & 84 & & 28.6 & 26.2 \\
\hline Loreto & & 17 & 50 & 11 & 44 & & 30.0 & 31.3 \\
\hline S. Ignacio & & & 148 & 80 & 15 & 54 & & 117.9 & 37.3 \\
\hline Corpus & & 20 & 52 & 20 & 47 & & 28.9 & 25.1 \\
\hline Trinidad & & 143 & 85 & 48 & 60 & & 115.4 & 50.3 \\
\hline Jesús & & 50 & 45 & 20 & 42 & & 50.0 & 31.6 \\
\hline San Carlos & Total de Entierros & 6 & 23 & 8 & 32 & & 12.2 & 32.3 \\
\hline San José & 1.874 & 19 & 47 & 9 & 19 & 548.6 & 46.7 & 28.4 \\
\hline Apóstoles & 2.262 & 15 & 18 & 5 & 25 & 602.7 & 25.1 & 22.4 \\
\hline Concep. & 2.168 & 102 & 46 & 7 & 38 & 332.2 & 35.0 & 27.0 \\
\hline Mártires & & 388 & 207 & 40 & 55 & & 184.2 & 34.2 \\
\hline La Mayor & & 1047 & 232 & 6 & 11 & & 565.4 & 23.9 \\
\hline San Javier & & 22 & 48 & 14 & 24 & & 37.3 & 22.2 \\
\hline S. Nicolás & & 1050 & 658 & 58 & 31 & & 336.8 & 43.5 \\
\hline San Luis & & 1457 & 988 & 37 & 34 & & 565.1 & 36.0 \\
\hline S. Lorenzo & & 1655 & 1026 & 31 & 18 & & 557.0 & 50.3 \\
\hline S. Miguel & & 68 & 78 & 43 & 53 & & 32.3 & 20.3 \\
\hline San Juan & & 241 & 135 & 1502 & 898 & & 75.0 & 485.0 \\
\hline Stos. Áng & & 137 & 121 & 66 & 74 & & 52.4 & 27.1 \\
\hline Sto. Tomé & & 332 & 139 & 13 & 20 & & 230.8 & 19.4 \\
\hline San Borja & & 76 & 35 & 25 & 63 & & 43.0 & 21.0 \\
\hline La Cruz & & 1086 & 519 & 81 & 105 & & 416.6 & 85.8 \\
\hline Yapeyú & & 45 & 163 & 52 & 162 & & 38.5 & 35.4 \\
\hline
\end{tabular}

\#Estimado.

Fuente: Catálogo de la numeración annual de las Doctrinas del Río Paraná Año 1739, Archivo General de la Nación, Buenos Aires, Sala 9-6-9-7; Catálogo de la numeración annual de los Pueblos del Río Uruguay, año de 1740, Archivo Nacional, Asunción Paraguay; Pablo Hernández, S.J., Organización social de las Doctrinas Guaraníes de la Compañía de Jesús, 2 vols. (Barcelona: Gustavo Gili Editor, 1913) 2: 616-617. 
Cuadro 3: Distribución de la población de las siete misiones orientales después de la sublevación Guaraní, 1756-1766.

\begin{tabular}{|c|c|c|c|c|c|c|}
\hline Misión & 1756 & 1759 & 1763 & 1764 & 1765 & 1766 \\
\hline En S. Miguel & & & 2705 & 2679 & 2864 & 3011 \\
\hline Jesús & & 31 & 31 & & & \\
\hline Trinidad & 45 & 158 & 124 & & & \\
\hline San Ignacio & & 25 & 6 & & & \\
\hline Apóstoles & & 5 & & & & \\
\hline Concepción & 863 & 685 & & & & \\
\hline La Mayor & & 2 & & & & \\
\hline San Carlos & & 69 & & & & \\
\hline Guazú & & 147 & & & & \\
\hline Sta. Rosa & 127 & 480 & 37 & & & \\
\hline San Cosme & & 431 & 232 & & & \\
\hline La Cruz & & 6 & & & & \\
\hline Estancia & & 2288 & & & & \\
\hline Ytapúa & & & 12 & & & \\
\hline Santiago & & & 5 & & & \\
\hline $\mathrm{La} \mathrm{Fe}$ & & & 50 & 47 & 47 & \\
\hline En S.Nicolás & & & 4123 & 3925 & 4006 & 3939 \\
\hline Jesús & & 353 & & & & \\
\hline Trinidad & & 108 & 5 & & & \\
\hline Concepción & 12 & & & & & \\
\hline Apóstoles & 402 & 1357 & & & & \\
\hline Candelaria & 2 & & & & & \\
\hline Guazú & & 815 & & & & \\
\hline Sta. Rosa & & 764 & 32 & & 22 & \\
\hline La Cruz & & 1 & & & & \\
\hline Estancia & & 1548 & & & & \\
\hline San Ignacio & & & 2 & & & \\
\hline Santiago & & & 4 & & & \\
\hline En S. Borja & & & 2321 & 2738 & 2631 & 2546 \\
\hline Ytapúa & 11 & 12 & 9 & & & \\
\hline Trinidad & & 23 & 68 & 63 & 36 & \\
\hline Jesús & & 50 & 97 & 82 & 77 & \\
\hline San Ignacio & & 16 & 36 & & & \\
\hline $\mathrm{La} \mathrm{Fe}$ & & 69 & 37 & & & \\
\hline Sta. Rosa & & 6 & 6 & & & \\
\hline Santiago & & 4 & & & & \\
\hline Candelaria & & 40 & & & & \\
\hline Apóstoles & 11 & & & & & \\
\hline
\end{tabular}


IHS. Antiguos jesuitas en Iberoamérica ISSN: 2314-3908 vol. 2 no 2 2014

\begin{tabular}{|c|c|c|c|c|c|c|}
\hline Misión & 1756 & 1759 & 1763 & 1764 & 1765 & 1766 \\
\hline Concepción & 5 & & & & & \\
\hline Sto. Tomé & 1641 & 3721 & & & & \\
\hline Loreto & & & 28 & & & \\
\hline En S. Luis & & & 1565 & 2381 & 2207 & 2194 \\
\hline Jesús & 419 & 478 & 538 & 545 & 569 & 534 \\
\hline Trinidad & 379 & 684 & 538 & 607 & 610 & 598 \\
\hline San Ignacio & & 9 & 9 & 9 & 10 & 11 \\
\hline San José & 1425 & 1395 & 325 & & & \\
\hline Apóstoles & 66 & 77 & & & & \\
\hline Concepción & 22 & & & & & \\
\hline San Carlos & 1518 & 1374 & 694 & 32 & 36 & 13 \\
\hline Santiago & & 4 & & & & \\
\hline La Cruz & & 48 & & & & \\
\hline Mártires & & & 6 & & & \\
\hline En San Lorenzo & & & 1419 & 1149 & 1185 & 1205 \\
\hline Ytapúa & 54 & 78 & 81 & & & \\
\hline Apóstoles & 24 & 7 & & & & \\
\hline Concepción & 4 & & & & & \\
\hline La Mayor & 1233 & 1533 & & & & \\
\hline San Carlos & & 3 & & & & \\
\hline Santiago & & 7 & 8 & & & \\
\hline San Cosme & & 193 & 156 & & & \\
\hline San Ignacio & & & 8 & 11 & & \\
\hline $\mathrm{La} \mathrm{Fe}$ & & & 13 & & & \\
\hline Sto. Tomé & 144 & & & & & \\
\hline En S. Juan & & & 906 & 1508 & 1515 & 2562 \\
\hline Ytapúa & 716 & 1064 & 942 & 886 & 915 & 940 \\
\hline Candelaria & 747 & 765 & 510 & & & \\
\hline Loreto & 605 & 857 & 443 & 316 & 321 & 136 \\
\hline San Ignacio & 747 & 885 & 781 & 770 & 804 & 147 \\
\hline Corpus & 532 & 494 & 424 & 317 & 361 & \\
\hline La Mayor & & 4 & & & & \\
\hline La Cruz & & 1 & & & & \\
\hline Mártires & & & 16 & 8 & & 6 \\
\hline En S. Ángel & & & 811 & 1310 & 1306 & 1509 \\
\hline Mártires & 674 & 1114 & 760 & 381 & 330 & 300 \\
\hline Ytapúa & 9 & 2 & & & & \\
\hline Trinidad & & 4 & & & & \\
\hline San Ignacio & & 24 & 33 & 29 & 33 & 29 \\
\hline
\end{tabular}




\begin{tabular}{|l|r|r|r|r|r|r|}
\hline \multicolumn{1}{|c|}{ Misión } & $\mathbf{1 7 5 6}$ & $\mathbf{1 7 5 9}$ & $\mathbf{1 7 6 3}$ & $\mathbf{1 7 6 4}$ & $\mathbf{1 7 6 5}$ & $\mathbf{1 7 6 6}$ \\
\hline Loreto & & 158 & 143 & 127 & & 51 \\
\hline Apóstoles & 9 & 20 & & & & \\
\hline Concepción & 440 & 675 & 538 & 354 & 418 & 342 \\
\hline La Mayor & & 1 & & & & \\
\hline San Javier & 1401 & 1914 & 1187 & 911 & 386 & 131 \\
\hline San Carlos & & 16 & & & & \\
\hline Sta. Rosa & & 3 & 9 & & & \\
\hline Santiago & & 139 & & & & \\
\hline La Cruz & & 5 & 98 & & & \\
\hline
\end{tabular}

Distribución de la población de las siete misiones orientales en otras misiones.

\begin{tabular}{|c|c|c|c|c|c|c|c|}
\hline Misión & $\mathbf{1 7 5 6}$ & $\mathbf{1 7 5 9}$ & $\mathbf{1 7 6 2}$ & $\mathbf{1 7 6 3}$ & $\mathbf{1 7 6 4}$ & $\mathbf{1 7 6 5}$ & $\mathbf{1 7 6 6}$ \\
\hline Candelaria & 749 & 805 & 551 & 510 & & & \\
\hline Corpus & & 494 & 472 & 424 & 317 & 361 & \\
\hline Loreto & 605 & 1,015 & 651 & 614 & 443 & 321 & 136 \\
\hline San Ignacio & 747 & 959 & 866 & 875 & 819 & 847 & 187 \\
\hline Trinidad & 424 & 977 & 846 & 735 & 670 & 646 & 598 \\
\hline San Cosme & & 624 & 668 & 388 & & & \\
\hline Jesús & 419 & 882 & 708 & 666 & 627 & 646 & 534 \\
\hline Ytapúa & 790 & 1,154 & 1,057 & 1,044 & 886 & 915 & 940 \\
\hline Santa Rosa & 127 & 1,273 & 122 & 84 & & 22 & \\
\hline Santiago & & 154 & 1,042 & 17 & & & \\
\hline La Fe & & 69 & 83 & 100 & 47 & 47 & \\
\hline Concepción & 1,346 & 1,360 & 552 & 538 & 354 & 418 & 342 \\
\hline San Xavier & 1,401 & 1,914 & 1,228 & 1,187 & 911 & 386 & 131 \\
\hline Mission & 1756 & 1759 & 1762 & 1763 & 1764 & 1765 & 1766 \\
\hline San Carlos & 1,518 & 1,462 & 1,170 & 694 & 32 & 36 & 13 \\
\hline San José & 1,425 & 1,395 & & 325 & & & \\
\hline Apóstoles & 512 & 1,466 & 109 & & & & \\
\hline Mártires & & & 926 & 782 & 389 & 330 & 306 \\
\hline La Mayor & & 1,536 & 33 & & & & \\
\hline Sto. Tomé & 1,785 & 3,721 & & & & & \\
\hline La Cruz & & 61 & & 98 & & & \\
\hline Estancias & & 3,836 & & & & & \\
\hline
\end{tabular}

Fuente: Pedro Vives Azancot, "Entre el esplendor y la decadencia: La población de misiones (17501759)”. Revista de Indias 42 , 1982, 541-544; Carmen Martínez Martín, "Datos estadísticos de población sobre las misiones del Paraguay, durante la demarcación del Tratado de Límites de 1750," Revista Complutense de Historia de América 24 (1998), 249-261; Familias, y Almas de los 7 Pueblos de la otra banda del Uruguay, y los Pueblos en que están repartidas,” 1763, 1764, y 1765, Archivo General de la Nación, Buenos Aires, Sala 9, 6-10-6; Las Familias de los 3 Pueblos S. Luis, S. Juan, y Sto. Ángel están repartidas en los Pueblos Siguientes, Archivo General de la Nación, Buenos Aires, Sala 9-6-10-6, Carta Anua 1756-1762, Biblioteca Nacional, Archivo General de la Nación, Buenos Aires, Ms. 4421 lat. 
Cuadro 4: Muertos de la epidemia de viruela y Tasa Bruta de Mortalidad en las Misiones Paraguay, 1764 y 1765.

\begin{tabular}{|c|c|c|c|c|}
\hline \multirow[b]{2}{*}{ Misión } & \multicolumn{2}{|c|}{ Entierros en: } & \multicolumn{2}{|c|}{ Tasa Bruta de Mortalidad/1000 } \\
\hline & 1764 & 1765 & 1764 & 1765 \\
\hline San Ignacio Guazú & 12 & 46 & 5.4 & 14.7 \\
\hline Nuestra Señora la Fe & 19 & 563 & 3.9 & 119.4 \\
\hline Santa Rosa & 1596 & & 484.8 & \\
\hline Santiago & 305 & & 99.3 & \\
\hline De Sto. Ángel en Ytapúa & 3 & & & \\
\hline San José & 398 & & 167.3 & \\
\hline San Carlos & 21 & & 9.3 & \\
\hline Apóstoles & 682 & & 268.1 & \\
\hline Concepción & 364 & & 114.2 & \\
\hline $\begin{array}{l}\text { De Sto. Ángel en } \\
\text { Concepción }\end{array}$ & 188 & & 349.4 & \\
\hline Mártires & 808 & 421 & 260.7 & 186.6 \\
\hline De Sto. Ángel en Mártires & 149 & & 196.1 & \\
\hline Sta. María la Mayor & & & 332.8 & 23.6 \\
\hline San Francisco Xavier & & 270 & & 156.6 \\
\hline $\begin{array}{l}\text { De Sto. Ángel en } \\
\text { SFX }\end{array}$ & 1 & & 1.0 & \\
\hline San Nicolás & 341 & & 82.7 & \\
\hline San Luis Gonzaga & 420 & & 268.4 & \\
\hline San Lorenzo & 234 & & 164.9 & \\
\hline San Miguel & 470 & & 173.8 & \\
\hline San Juan Bautista & 5 & & 5.5 & \\
\hline San Francisco de Borja & 153 & 203 & 65.9 & 70.2 \\
\hline Santo Tomé & 570 & & 179.4 & \\
\hline La Cruz & 7 & 571 & 2.0 & 160.0 \\
\hline Candelaria & & 1 & & 0.4 \\
\hline Santa Ana & & 38 & & 10.0 \\
\hline Loreto & & 1833 & & 371.3 \\
\hline De San Juan en Loreto & & 25 & & 79.1 \\
\hline San Ignacio Miní & & 16 & & 5.2 \\
\hline Corpus Christi & & 6 & & 1.4 \\
\hline Jesús & & 33 & & 14.0 \\
\hline De Sto. Ángel en varias misiones & & 560 & & 180.0 \\
\hline Total & 7414 & 4615 & & \\
\hline
\end{tabular}


Fuente: Muertos de la Epidemia de Viruelas este Año de 1764, Archivo General de la Nación, Buenos Aires, Sala 9-6-10-6; Difuntos de Viruelas, Archivo General de la Nación, Buenos Aires, Sala 9-6-10-6.

Cuadro 5: Bautismos y entierros registrados en Santa Rosa, 1753-1765.

\begin{tabular}{|c|c|c|c|c|c|}
\hline Año & Bautismos & Entierros & Cambio +/- & $\begin{array}{c}\text { Tasa Bruta } \\
\text { de } \\
\text { Natalidad }\end{array}$ & $\begin{array}{l}\text { Tasa Bruta } \\
\text { de } \\
\text { Mortalidad }\end{array}$ \\
\hline 1753 & 175 & 110 & 65 & & \\
\hline 1754 & 176 & 103 & 73 & 63.1 & 36.3 \\
\hline 1755 & 153 & & & & \\
\hline 1756 & 180 & 113 & 67 & 80.2 & 7.8 \\
\hline 1757 & 185 & & & & \\
\hline 1758 & 161 & & & & \\
\hline 1759 & 168 & 130 & 38 & 53.7 & 41.8 \\
\hline 1760 & 203 & & & & \\
\hline 1761 & 190 & & & & \\
\hline 1762 & 202 & 177 & 25 & 61.8 & 54.7 \\
\hline 1763 & 183 & 228 & -45 & 57.1 & 69.2 \\
\hline 1764 & 211 & 1,614 & $-1,403$ & 64.1 & 490.3 \\
\hline 1765 & 59 & 211 & -152 & 29.0 & 40.9 \\
\hline
\end{tabular}

Fuente: Santa Rosa Registro de bautismos, Archivo Parroquial de Santa Rosa, Paraguay.

Cuadro 6: Estructura de la población de Nuestra Señora de los Reyes de Yapeyú, 1771.

\begin{tabular}{|c|c|c|c|c|c|c|}
\hline $\begin{array}{c}\text { Tamaño de la } \\
\text { familia }\end{array}$ & $\begin{array}{c}\text { \# de } \\
\text { Familias }\end{array}$ & \# de gente & Huérfanos & Huérfanas & Viudas & Viudos \\
\hline 2 & 236 & 472 & 442 & 398 & 278 & 101 \\
\hline 3 & 170 & 510 & & & & \\
\hline 4 & 109 & 436 & & & & \\
\hline 5 & 51 & 255 & & & & \\
\hline 6 & 17 & 102 & & & & \\
\hline 7 & 17 & 119 & & & & \\
\hline 8 & 8 & 64 & & & & \\
\hline
\end{tabular}

Fuente: Padrón de Nuestra Señora de los Reyes de Yapeyú, Archivo General de la Nación, Buenos Aires, Sala 9-18-8-7.

Cuadro 7: Población y tasas vitales de San Nicolás.

\begin{tabular}{|l|c|c|c|c|c|c|c|}
\hline Año & Población & Familias & Bautismos & Entierros & TBN & TBM & TPF \\
\hline 1690 & 3648 & 870 & 25 & 96 & $6.7^{* * *}$ & $25.8^{*}$ & 4.2 \\
\hline 1694 & 5315 & 1040 & 243 & 199 & $19.0^{* * *}$ & $37.8^{*}$ & 5.1 \\
\hline 1698 & 5819 & 1066 & 259 & 136 & $45.5^{*}$ & $23.9^{*}$ & 5.5 \\
\hline
\end{tabular}


IHS. Antiguos jesuitas en Iberoamérica ISSN: 2314-3908

\begin{tabular}{|l|c|c|c|c|c|c|c|}
\hline 1700 & 5279 & 1119 & 315 & 159 & $61.5^{*}$ & $31.0^{*}$ & 4.7 \\
\hline 1702 & 4699 & 1216 & 335 & 225 & $73.0^{*}$ & $49.0^{*}$ & 3.9 \\
\hline 1705 & 4927 & 1208 & 350 & 176 & $73.7^{*}$ & $35.9^{*}$ & 4.1 \\
\hline 1707 & 5386 & 1262 & 327 & 211 & $62.0^{*}$ & $40.0^{*}$ & 4.3 \\
\hline 1724 & 6667 & 1455 & 472 & 248 & $73.3^{*}$ & $38.5^{*}$ & 4.6 \\
\hline 1728 & 7055 & 1697 & 502 & 272 & $73.6^{*}$ & $39.9^{*}$ & 4.2 \\
\hline 1733 & 7415 & 1812 & 495 & 799 & $64.1^{*}$ & $103.5^{*}$ & 4.1 \\
\hline 1736 & 6104 & 866 & 230 & 726 & 2.9 & 103.9 & 7.1 \\
\hline 1739 & 2048 & 445 & 92 & 1675 & 10.7 & 336.8 & 4.6 \\
\hline 1740 & 2194 & 546 & 214 & 89 & 104.5 & 43.5 & 4.0 \\
\hline 1741 & 2279 & 553 & 184 & 81 & 83.9 & 36.9 & 4.1 \\
\hline 1744 & 2834 & 695 & 184 & 201 & $64.4^{*}$ & $72.8^{*}$ & 4.1 \\
\hline 1745 & 3530 & 916 & 298 & 141 & 95.9 & 83.7 & 3.9 \\
\hline 1746 & 4074 & 962 & 404 & 180 & 114.5 & 51.0 & 4.2 \\
\hline 1747 & 4114 & 933 & 349 & 147 & 85.7 & 36.1 & 4.4 \\
\hline 1748 & 4245 & 962 & 401 & 163 & 97.5 & 39.6 & 4.4 \\
\hline 1749 & 3913 & 986 & 351 & 430 & 82.7 & 101.3 & 4.0 \\
\hline 1750 & 4255 & 1024 & 393 & 164 & 100.4 & 41.9 & 4.2 \\
\hline 1753 & 4724 & 1028 & 372 & 159 & $82.5^{*}$ & $35.3^{*}$ & 4.6 \\
\hline 1754 & 4863 & 1035 & 360 & 195 & 76.2 & 41.3 & 4.7 \\
\hline 1756 & 416 & 67 & N/A & N/A & N/A & N/A & 6.2 \\
\hline 1759 & 4278 & 848 & 261 & 194 & $62.0^{*}$ & $46.1^{*}$ & 5.1 \\
\hline 1762 & 4429 & 834 & 249 & 254 & 55.9 & 57.0 & 5.3 \\
\hline 1763 & 4166 & 777 & 178 & 254 & 40.2 & 57.4 & 5.4 \\
\hline 1764 & 3925 & 683 & 238 & 528 & 49.9 & 126.7 & 5.8 \\
\hline 1765 & 4028 & 831 & 204 & 119 & 52.0 & 30.3 & 4.9 \\
\hline 1767 & 3811 & 791 & 197 & 151 & 50.0 & 38.3 & 4.8 \\
\hline 1797 & 2443 & 603 & 118 & 142 & $47.8^{*}$ & $57.6^{*}$ & 4.1 \\
\hline 1798 & 2370 & 566 & 78 & 126 & 31.9 & 51.6 & 4.2 \\
\hline 1799 & 2381 & 546 & 100 & 104 & 42.2 & 43.9 & 4.4 \\
\hline$* 519$ & & & & & & \\
\hline 179 & & & & & & & \\
\hline
\end{tabular}

*Estimado.

** Posible subregistro de nacimientos.

TBN-Tasa Bruta de Natalidad; TBM-Tasa Bruta de Mortalidad; TPF-Tamaño Promedio de la Familia. Fuente: "The Population and Vital Rates of the Jesuit Missions of Paraguay 1700-1767," Journal of Interdisciplinary History 28:3 (winter 2008), 417.

Cuadro 8: Población y tasas vitales de San Estanislao y San Joaquín, en años selectos.

San Estanislao

\begin{tabular}{|c|c|c|c|c|c|c|c|}
\hline Año & Familias & Población & Bautismos & Entierros & TBN & TBM & TPF \\
\hline 1750 & & 735 & & & & & \\
\hline 1753 & 137 & 808 & 62 & 18 & $76.3^{*}$ & $22.1^{*}$ & 5.9 \\
\hline 1754 & 180 & 600 & & & & & 3.3 \\
\hline
\end{tabular}

120 Robert H. Jackson. Comprendiendo los efectos de las enfermedades del Viejo Mundo...88-133. 


\begin{tabular}{|l|c|c|c|c|c|c|c|}
\hline 1755 & 150 & 835 & & & & & \\
\hline 1757 & 223 & 941 & - & - & - & - & 4.2 \\
\hline 1759 & 234 & 1,090 & 230 & 68 & $247.8^{*}$ & $73.3^{*}$ & 4.7 \\
\hline 1760 & 240 & 943 & - & - & - & - & 3.9 \\
\hline 1762 & 279 & 1,182 & 210 & 42 & 217.2 & 43.4 & 4.3 \\
\hline 1763 & 321 & 1,429 & 209 & 110 & 176.8 & 93.1 & 4.5 \\
\hline 1765 & 383 & 1,730 & 180 & 87 & $110.0^{*}$ & $53.2^{*}$ & 4.5 \\
\hline 1766 & 415 & 1,930 & 149 & 37 & 86.1 & 21.4 & 4.7 \\
\hline
\end{tabular}

San Joaquín

\begin{tabular}{|c|c|c|c|c|c|c|c|}
\hline Año & Familias & Población & Bautismos & Entierros & TBN & TBM & TPF \\
\hline 1750 & & 702 & & & & & \\
\hline 1752 & 208 & 1152 & & & & & \\
\hline 1753 & 200 & 1,046 & 35 & 32 & $33.3^{*}$ & $30.4^{*}$ & 5.2 \\
\hline 1754 & 200 & 1,088 & 73 & 16 & 69.8 & 15.3 & 5.4 \\
\hline 1755 & 206 & 1074 & & & & & \\
\hline 1757 & 222 & 1,112 & - & - & - & - & 5.0 \\
\hline 1759 & 267 & 1,280 & 99 & 36 & $81.4^{*}$ & $28.1^{*}$ & 4.8 \\
\hline 1760 & 270 & 1,287 & - & - & - & - & 4.8 \\
\hline 1762 & 268 & 1,415 & 84 & 30 & 66.8 & 23.9 & 5.3 \\
\hline 1763 & 355 & 1,707 & 94 & 85 & 66.4 & 60.1 & 4.8 \\
\hline 1765 & 372 & 1,755 & 119 & 152 & $66.6^{*}$ & $85.0^{*}$ & 4.7 \\
\hline 1766 & 388 & 1,440 & 143 & 74 & 81.5 & 42.2 & 3.7 \\
\hline
\end{tabular}

*Estimado; TBN-Tasa Bruta de Natalidad; TBM-Tasa Bruta de Mortalidad; TPF-Tamaño Promedio de la Familia.

Fuente: Pedro Vives Azancot, "Entre el esplendor y la decadencia: La población de misiones (17501759)". Revista de Indias 42 (1982), 541-544; censos para los años 1750, 1752, 1753, 1754, 1759, 1762, 1763, 1764, 1765 con título Catalogo de la numeración annual de las Doctrinas del Río Paraná Año, Catalogo de la numeración annual de las Doctrinas del Río Uruguay; Archivo General de la Nación, Buenos Aires, Sala 9-6-10-6; Annua Enumeratio Reductionum Anni 1755, Archivo General de la Nación, Buenos Aires, Sala 9-6-10-6; Annua Enumeratio Reductionum Anni 1757, Archivo General de la Nación, Buenos Aires, Sala 9-6-10-6; Annua Enumeratio Reductionum Anni 1760, Archivo General de la Nación, Buenos Aires, Sala 9-6-10-6; Las Familias de los 3 Pueblos S Luis, S Juan, y Sto Ángel están repartidas en los Pueblos Siguientes, Archivo General de la Nación, Buenos Aires, Sala 9-6-10-6.

Cuadro 9: Bautismos, entierros y población de San Fernando de Abipones, 1753-1762.

\begin{tabular}{|c|c|c|c|c|c|c|c|c|c|}
\hline \multirow[b]{2}{*}{ Año } & \multirow[b]{2}{*}{ Población } & \multirow[b]{2}{*}{ Familias } & \multicolumn{2}{|c|}{ Bautismos } & \multirow{2}{*}{$\begin{array}{c}\text { En } \\
\text { artículo } \\
\text { mortis }\end{array}$} & \multirow[b]{2}{*}{ Entierros } & \multirow[b]{2}{*}{ TBN } & \multirow[b]{2}{*}{ YBM } & \multirow[b]{2}{*}{ TPF } \\
\hline & & & Párvulos & Adultos & & & & & \\
\hline 1753 & 679 & 156 & 12 & 3 & 1 & 2 & $17.9 *$ & $3.0 *$ & 4.4 \\
\hline 1754 & 455 & 104 & 18 & 2 & 0 & 5 & 26.5 & 7.4 & 4.4 \\
\hline 1755 & 344 & 80 & 12 & 4 & 3 & 3 & 26.4 & 6.6 & 4.3 \\
\hline
\end{tabular}

121 Robert H. Jackson. Comprendiendo los efectos de las enfermedades del Viejo Mundo...88-133. 


\begin{tabular}{|r|r|r|r|r|r|r|r|r|r|}
\hline 1756 & 355 & 82 & 8 & 0 & 1 & 3 & 23.3 & 8.7 & 4.3 \\
\hline 1757 & 363 & 82 & 6 & 0 & 2 & 4 & 8.5 & 11.3 & 4.4 \\
\hline 1758 & 151 & 39 & 3 & 0 & 1 & 3 & 8.3 & 8.3 & 3.9 \\
\hline 1759 & 338 & 76 & 9 & 0 & 0 & 3 & 59.6 & 19.9 & 4.5 \\
\hline 1760 & 339 & 74 & 16 & 0 & 3 & 3 & 26.6 & 8.9 & 4.6 \\
\hline 1761 & 273 & 56 & 10 & 1 & 2 & 2 & 29.5 & 5.9 & 4.9 \\
\hline 1762 & 284 & 48 & 6 & 0 & 0 & 2 & 22.0 & 7.3 & 5.9 \\
\hline
\end{tabular}

*Estimado.

Fuente: Anua del Pueblo de S[a]n Fern[and]o Desde el Año 1753, Archivo General de la Nación, Buenos Aires, Sala 9-10-6-10.

Cuadro 10: La población femenina como porcentaje de la población total de San Fernando de Abipones, 1753-1762, 1766.

\begin{tabular}{|c|c|c|c|}
\hline Año & Porcentaje & Año & Porcentaje \\
\hline 1753 & 57.0 & 1759 & 58.0 \\
\hline 1754 & 58.5 & 1760 & 57.8 \\
\hline 1755 & 57.6 & 1761 & 60.0 \\
\hline 1756 & 58.0 & 1762 & 59.2 \\
\hline 1757 & 58.1 & 1766 & 54.0 \\
\hline 1758 & 59.6 & & \\
\hline
\end{tabular}

Fuente: Anua del Pueblo de S[a]n Fern[and]o Desde el Año 1753, Archivo General de la Nación, Buenos Aires, Sala 9-10-6-10.

\section{Apéndice: Población de las Misiones de Paraguay}

Este apéndice resume las cifras de población para las misiones de Paraguay individuales en años seleccionados. Estas cifras se han tomado de los censos de manuscritos del Archivo General de la Nación in Buenos Aires (AGN), el Archivo Nacional de Paraguay (ANP) en Asunción, y el Archivo General de las Indias (AGI) in Sevilla, España: para los años 1702, 1711, 1714. 1715, 1716, 1717, 1720, 1724, 1728 1731, 1733, 1735, 1736,1738, 1739, 1740, 1741, 1744, 1745, 1746, 1747, 1748, 1749, 1750, 1752, 1753, 1754, 1755, 1756, 1757, 1759, 1760, 1762, 1763, 1764, 1765, y 1767 del AGN, Sala IX-7-2-1, 6-9-6, 6-97, 6-10-6; "Empadronamiento de las Treinta Pueblos de Misiones, por el Coronel Don Marcos de Larrazabal,” 1772 AGN, Sala IX-18-8-4; censuses for 1797 from AGN, Sala IX-18-6-5; for 1798 from AGN, Sala IX-18-2-4; 1799 AGN, Sala IX-18-2-5; padrones de tributarios del año 1801 del AGN, Sala 917-3-6. Censo para el año 1724 del ANP. Para el año 1702 del informe de Francisco Burges, S.J., sin lugar, sin fecha [1705], "Francisco Burges de la Compañia de Jesús, Procurador de la Provincia de Paraguay,” AGI, Charcas 381. Ver tambien Robert H. Jackson, Missions and the Frontiers of Spanish America: A comparative study of the impact of environmental, economic, political, and socio-cultural variations on the missions in the Río de la Plata Region and on the Northern Frontier of New Spain (Scottsdale: Pentacle Press, 2005), 463-476; Aurelio Porto, Historia das Missões Orientais, 2 volumenes (Porto Alegre: Livraria Selbach, 1954).

1643-1691

\begin{tabular}{|l|l|l|l|l|l|l|l|l|}
\hline Misión & $\mathbf{1 6 4 3}$ & $\mathbf{1 6 4 7}$ & $\mathbf{1 6 5 7}$ & $\mathbf{1 6 6 7}$ & $\mathbf{1 6 7 1}$ & $\mathbf{1 6 7 6}$ & $\mathbf{1 6 8 2}$ & $\mathbf{1 6 9 1}$ \\
\hline Guazú & 998 & 1150 & 1327 & 1940 & 2150 & 2326 & 2741 & 3095 \\
\hline Ytapúa & 2199 & 1700 & 2292 & 2735 & 3023 & 3094 & 3288 & \\
\hline
\end{tabular}




\begin{tabular}{|l|l|l|l|l|l|l|l|l|}
\hline Jesús & & & & & & & & 840 \\
\hline Candelaria & 1490 & 1077 & 1471 & 2363 & 2100 & 1991 & 1868 & 2508 \\
\hline S. Cosme & 2100 & 1075 & 1376 & & & 1210 & 1283 & 1452 \\
\hline S. Ana & 850 & 779 & 1024 & 1300 & 1318 & 1352 & 1415 & 1758 \\
\hline Loreto & 1476 & 1700 & 1920 & 2089 & 2366 & 2358 & 2772 & 3620 \\
\hline S. I. Miní & 1750 & 1708 & 2171 & 2439 & 2212 & 2253 & 2441 & 2282 \\
\hline S. Carlos & 2300 & 1701 & 2123 & 2714 & 2998 & 3633 & 4420 & 4630 \\
\hline S. José & 1441 & 1334 & 1268 & & 1684 & & 2272 & 2472 \\
\hline Corpus & 1604 & 1300 & 1331 & & & & 1350 & 1655 \\
\hline Apóstoles & 1635 & 1144 & 3239 & & & 2158 & 3548 & \\
\hline S. Nicolás & 1803 & 1854 & 3684 & & & 2921 & 3548 & 3894 \\
\hline San Luis & & & & & & & & 3049 \\
\hline Concepción & 3665 & 1469 & 3275 & & 4944 & 6035 & 7014 & 4589 \\
\hline S. Javier & 1442 & 1300 & 1604 & & 2388 & 2740 & 3029 & 3883 \\
\hline La Mayor & 2637 & 2000 & 2776 & & 4040 & 4378 & 5171 & 2353 \\
\hline Mártires & 1040 & 1186 & 1278 & & 1338 & 1769 & 1980 & 2317 \\
\hline S. Miguel & 1860 & 1165 & 2101 & & & 3830 & 3740 & \\
\hline La Cruz & 1300 & 1472 & 1514 & & & 2212 & 2251 & \\
\hline Sto. Tomé & 3000 & 1960 & 3494 & & & 5129 & 5243 & \\
\hline Yapeyú & 1600 & 1600 & 1828 & & 2000 & 2100 & 2477 & 1865 \\
\hline
\end{tabular}

1702-1716

\begin{tabular}{|l|l|l|l|l|l|l|}
\hline Misión & $\mathbf{1 7 0 2}$ & $\mathbf{1 7 0 8}$ & $\mathbf{1 7 1 1}$ & $\mathbf{1 7 1 4}$ & $\mathbf{1 7 1 5}$ & $\mathbf{1 7 1 6}$ \\
\hline Guazú & 3700 & 4950 & & 5330 & 5330 & 5511 \\
\hline La Fe & 2739 & 3215 & & 4351 & 4727 & 4481 \\
\hline S. Rosa & 2879 & 3599 & & 4093 & 4184 & 4268 \\
\hline Santiago & 3680 & 3936 & & 3596 & 3885 & 4292 \\
\hline Ytapúa & 4800 & 4874 & & 5472 & 5521 & 5471 \\
\hline Candelaria & 2596 & 2325 & & 3111 & 3178 & 3276 \\
\hline S. Cosme & 1573 & 1622 & & 1980 & 2050 & 2121 \\
\hline S. Ana & 2225 & 2444 & & 2800 & 2831 & 2961 \\
\hline Loreto & 4060 & 4569 & & 5161 & 5543 & 5426 \\
\hline S. I. Miní & 2080 & 2376 & & 2826 & 2840 & 3037 \\
\hline Corpus & 2184 & 2436 & & 2763 & 2490 & 2833 \\
\hline Trinidad & N/A & 2790 & & 3200 & 2758 & 2835 \\
\hline Jesús & 1018 & 1025 & & 1420 & 2085 & 1544 \\
\hline S. Carlos & 5355 & 2792 & & 3314 & 3302 & 3513 \\
\hline S. José & 2594 & 2735 & & 3135 & 3186 & 3421 \\
\hline
\end{tabular}


IHS. Antiguos jesuitas en Iberoamérica ISSN: 2314-3908

\begin{tabular}{|l|l|l|l|l|l|l|}
\hline Apóstoles & 3536 & 3849 & 3884 & 3522 & 4386 & 4543 \\
\hline Concepción & 5653 & 3416 & 3371 & 3638 & 3285 & 4116 \\
\hline Mártires & 2124 & 2835 & 2897 & 3035 & 3217 & 3203 \\
\hline La Mayor & 2869 & 3303 & 3022 & 2285 & 2970 & 3311 \\
\hline S. Javier & 4117 & 4942 & 4933 & 4989 & 5201 & 7641 \\
\hline S. Nicolás & 4699 & 5833 & 5969 & 6519 & 6658 & 6912 \\
\hline S. Luis & 3473 & 4922 & 3339 & 3588 & 3830 & 4283 \\
\hline S. Lorenzo & 4427 & 4640 & 4271 & 4518 & 4760 & 4814 \\
\hline S. Miguel & 2197 & 3188 & 3254 & 2972 & 2823 & 2876 \\
\hline S. Juan & 2650 & 3434 & 3088 & 3783 & 3850 & 3813 \\
\hline Sto. Ángel. & N/A & 3074 & 2761 & 2853 & 3026 & 3194 \\
\hline Sto.Tomé & 3416 & 3887 & 4284 & 4553 & 4687 & 5683 \\
\hline S. Borja & 2600 & 2897 & 3081 & 3368 & 3391 & 3514 \\
\hline La Cruz & 3851 & 4139 & 4755 & 4824 & 4912 & 5275 \\
\hline Yapeyú & 2206 & 2570 & 2318 & 2790 & 2806 & 4283 \\
\hline
\end{tabular}

1717-1733

\begin{tabular}{|l|l|l|l|l|l|l|}
\hline Misión & $\mathbf{1 7 1 7}$ & $\mathbf{1 7 2 0}$ & $\mathbf{1 7 2 4}$ & $\mathbf{1 7 2 8}$ & $\mathbf{1 7 3 1}$ & $\mathbf{1 7 3 3}$ \\
\hline Guazú & 5651 & 2738 & 3343 & 3368 & 3195 & 1266 \\
\hline La Fe & 4404 & 5557 & 5463 & 6713 & 6515 & 4251 \\
\hline S. Rosa & 5389 & 4230 & 4742 & 6064 & 6093 & 2775 \\
\hline Santiago & 4387 & 2135 & 2720 & 3128 & 3524 & 3479 \\
\hline Ytapúa & 5871 & 5163 & 5357 & 5336 & 6548 & 6396 \\
\hline Candelaria & 3275 & 2596 & 2863 & 3294 & 3317 & 3134 \\
\hline S. Cosme & 2033 & 1855 & 2120 & 2286 & 2306 & 2145 \\
\hline S. Ana & 3032 & 3117 & 3600 & 3788 & 4527 & 3716 \\
\hline Loreto & 5526 & 5617 & 6113 & 6854 & 7048 & 6077 \\
\hline S. I. Miní & 3040 & 2865 & 3138 & 3330 & 4356 & 3959 \\
\hline Corpus & 2816 & 3157 & 3584 & 4051 & 4400 & 4008 \\
\hline Trinidad & 2925 & 2771 & 3140 & 3703 & 3569 & 3598 \\
\hline Jesús & 1527 & 1790 & 1947 & 2158 & 2436 & 2241 \\
\hline S. Carlos & 3596 & 2795 & 3065 & 2702 & 3388 & 3369 \\
\hline S. José & 3510 & 2819 & 3274 & 3500 & 3720 & 3605 \\
\hline Apóstoles & 3996 & 3235 & 4140 & 4746 & 5185 & 5267 \\
\hline Concepción & 4186 & 3936 & 4894 & 5331 & 5848 & 5881 \\
\hline Mártires & 3265 & 3222 & 3343 & 3637 & 3874 & 3665 \\
\hline La Mayor & 3134 & 3249 & 3490 & 3775 & 3902 & 3585 \\
\hline S. Javier & 5600 & 5280 & 3409 & 3776 & 3813 & 3663 \\
\hline
\end{tabular}


IHS. Antiguos jesuitas en Iberoamérica ISSN: 2314-3908

\begin{tabular}{|l|l|l|l|l|l|l|}
\hline S. Nicolás & 6993 & 6072 & 6667 & 7055 & 7690 & 7415 \\
\hline S. Luis & 5326 & 4324 & 5045 & 5821 & 6149 & 5619 \\
\hline S. Lorenzo & 4905 & 4967 & 5224 & 5899 & 6420 & 6100 \\
\hline S. Miguel & 2909 & 3598 & 3972 & 4569 & 4904 & 4465 \\
\hline S. Juan & 3472 & 3946 & 4629 & 3914 & 4503 & 4968 \\
\hline Sto. Ángel. & 3239 & 3592 & 4052 & 4512 & 4601 & 4925 \\
\hline Sto.Tomé & 4768 & 2659 & 2949 & 3393 & 3545 & 3494 \\
\hline S. Borja & 3757 & 2864 & 2906 & 3366 & 3629 & 3658 \\
\hline La Cruz & 5481 & 3069 & 3615 & 4057 & 4573 & 4345 \\
\hline Yapeyú & 2873 & 1886 & 4360 & 4775 & 5666 & 5374 \\
\hline
\end{tabular}

1736-1747

\begin{tabular}{|l|l|l|l|l|l|l|l|l|l|}
\hline Misión & $\mathbf{1 7 3 6}$ & $\mathbf{1 7 3 8}$ & $\mathbf{1 7 3 9}$ & $\mathbf{1 7 4 0}$ & $\mathbf{1 7 4 1}$ & $\mathbf{1 7 4 4}$ & $\mathbf{1 7 4 5}$ & $\mathbf{1 7 4 6}$ & $\mathbf{1 7 4 7}$ \\
\hline Guazú & 1576 & 1846 & 1964 & 2018 & 2152 & 2231 & 2238 & 2226 & 2247 \\
\hline La Fe & 2595 & 2701 & 2903 & 3086 & 3298 & 3593 & 3796 & 4183 & 4084 \\
\hline S. Rosa & 1671 & 1828 & 1916 & 1973 & 2031 & 2170 & 2215 & 2288 & 2354 \\
\hline Santiago & 3740 & 3955 & 4081 & 4128 & 4276 & 4389 & 4484 & 4597 & 4595 \\
\hline Ytapúa & 4650 & 2690 & 2591 & 2179 & 2106 & 2847 & 2969 & 3039 & 3400 \\
\hline Candelaria & 3048 & 1511 & 1503 & 1441 & 1639 & 1764 & 1814 & 1881 & 1933 \\
\hline S. Cosme & 1531 & 1225 & 1236 & 1209 & 1094 & 1272 & 1325 & 1402 & 1413 \\
\hline S. Ana & 4055 & 4343 & 4397 & 4533 & 4505 & 4331 & 4214 & 4386 & 4458 \\
\hline Loreto & 1937 & 2234 & 1756 & 2246 & 2422 & 2789 & 2855 & 2946 & 3028 \\
\hline S. I. Miní & 1808 & 1934 & 1849 & 1933 & 2076 & 2218 & 2297 & 2392 & 2397 \\
\hline Corpus & 2190 & 1975 & 2667 & 2808 & 2922 & 3241 & 3364 & 3488 & 3619 \\
\hline Trinidad & 1733 & 1975 & 2149 & 2268 & 2047 & 2245 & 2484 & 2595 & 2517 \\
\hline Jesús & 2204 & 1902 & 1962 & 1836 & 1850 & 1679 & 1722 & 1729 & 1737 \\
\hline S. Carlos & 3212 & 2377 & 1239 & 1140 & 1273 & 1404 & 1595 & 1494 & 1663 \\
\hline S. José & 3382 & 1392 & 1338 & 1390 & 1411 & 1594 & 1669 & 1745 & 1816 \\
\hline Apóstoles & 3716 & 1315 & 1341 & 1494 & 1582 & 1577 & 1728 & 1849 & 1851 \\
\hline Concepción & 6460 & 4234 & 1669 & 1944 & 2369 & 2296 & 2192 & 2242 & 2321 \\
\hline Mártires & 3396 & 3230 & 2777 & 2829 & 2839 & 2834 & 2847 & 2930 & 2974 \\
\hline La Mayor & 2232 & 2262 & 711 & 819 & 894 & 993 & 1823 & 2012 & 2028 \\
\hline S. Javier & 2873 & 1876 & 1710 & 1789 & 1894 & 1895 & 1905 & 1914 & 1913 \\
\hline S. Nicolás & 6104 & 5071 & 1772 & 2194 & 2279 & 3107 & 3530 & 4074 & 4114 \\
\hline S. Luis & 4445 & 4327 & 1978 & 2308 & 2432 & 2868 & 2968 & 3096 & 3275 \\
\hline S. Lorenzo & 4405 & 4814 & 974 & 1173 & 1311 & 1573 & 1563 & 1720 & 1870 \\
\hline S. Miguel & 4156 & 4522 & 4741 & 4740 & 4974 & 6611 & 6675 & 6852 & 6765 \\
\hline S. Juan & 5110 & 5012 & 4949 & 2171 & 2525 & 2843 & 2925 & 3001 & 3134 \\
\hline
\end{tabular}

125 Robert H. Jackson. Comprendiendo los efectos de las enfermedades del Viejo Mundo...88-133. 


\begin{tabular}{|l|l|l|l|l|l|l|l|l|l|}
\hline Sto. Ángel. & 4336 & 4921 & 5163 & 5228 & 5199 & 4824 & 4818 & 4788 & 4957 \\
\hline Sto.Tomé & 3211 & 2041 & 1699 & 1892 & 2063 & 2397 & 2498 & 2555 & 2662 \\
\hline S. Borja & 3358 & 2998 & 3244 & 3291 & 3430 & 3814 & 3924 & 4081 & 3233 \\
\hline La Cruz & 4304 & 3853 & 2167 & 2163 & 2314 & 2540 & 2656 & 2755 & 2582 \\
\hline Yapeyú & 5283 & 5410 & 5713 & 5687 & 5748 & 6187 & 6147 & 6419 & 6741 \\
\hline
\end{tabular}

1735

\begin{tabular}{|c|c|c|}
\hline Misión & Padrones de Tributarios & Carta Annua \\
\hline Guazú & 1655 & 1631 \\
\hline $\mathrm{La} \mathrm{Fe}$ & 2294 & 2492 \\
\hline S. Rosa & 2265 & 1859 \\
\hline Santiago & & 3611 \\
\hline Ytapúa & & 4382 \\
\hline Candelaria & & 3107 \\
\hline S. Cosme & 2143 & 1986 \\
\hline S. Ana & 3077 & 4278 \\
\hline Loreto & 2492 & 4284 \\
\hline S. I. Miní & 3738 & 2788 \\
\hline Corpus & 4887 & 1798 \\
\hline Trinidad & 1837 & 2033 \\
\hline Jesús & 2392 & 2218 \\
\hline S. Carlos & 2400 & 3216 \\
\hline S. José & & 3673 \\
\hline Apóstoles & 3884 & 3833 \\
\hline Concepción & 5920 & 6452 \\
\hline Mạrtires & 3416 & 3406 \\
\hline La Mayor & 2903 & 2344 \\
\hline S. Javier & 3494 & 3275 \\
\hline S. Nicolás & 6986 & 6594 \\
\hline S. Luis & 5305 & 4689 \\
\hline S. Lorenzo & 5177 & 4548 \\
\hline S. Miguel & 4019 & 4073 \\
\hline S. Juan & 4621 & 5129 \\
\hline Sto. Ángel & 4501 & 4557 \\
\hline Sto. Tomé & 3282 & 3176 \\
\hline S. Borja & 3584 & 3277 \\
\hline La Cruz & 4372 & 4369 \\
\hline Yapeyú & 5106 & 5150 \\
\hline
\end{tabular}

Fuente: Padrones de tributarios, AGN, Sala 9-18-8-4; 1735 Carta Annua, 1735, AGN, Sala 9-6-9-6. 


\begin{tabular}{|c|c|c|c|c|c|c|c|c|c|c|}
\hline Misión & 1748 & 1749 & 1750 & 1752 & 1753 & 1754 & 1755 & 1756 & 1757 & 1759 \\
\hline Guazú & 2167 & 2251 & 2251 & 2254 & 2399 & 2477 & 2440 & 2472 & 2420 & 2332 \\
\hline $\mathrm{La} \mathrm{Fe}$ & 4240 & 4246 & 4296 & 4568 & 4550 & 4741 & 4881 & 4853 & 4713 & 4792 \\
\hline S. Rosa & 2455 & 2524 & 2524 & 2780 & 2838 & 2921 & 3051 & 3056 & 3124 & 3150 \\
\hline Santiago & 4633 & 3968 & 3968 & 4004 & 4085 & 4184 & 4263 & 4304 & 4464 & 4122 \\
\hline Ytapúa & 3518 & 3354 & 3276 & 3370 & 3514 & 3736 & 3503 & 3789 & 3758 & 4149 \\
\hline Candelaria & 2017 & 2031 & 2031 & 2202 & 2253 & 2760 & 2338 & 2409 & 2428 & 2585 \\
\hline S. Cosme & 1432 & 1449 & 1449 & 1446 & 1555 & 1591 & 1622 & 1632 & 1647 & 1672 \\
\hline S. Ana & 4787 & 4778 & 4778 & 4622 & 4780 & 4944 & 5071 & 5040 & 5166 & 5191 \\
\hline Loreto & 3195 & 3276 & 3276 & 3585 & 3732 & 3754 & 3859 & 4023 & 4157 & 4398 \\
\hline S. I. Miní & 2476 & 2520 & 2520 & 2722 & 2771 & 2863 & 2771 & 2773 & 2905 & 3051 \\
\hline Corpus & 3800 & 3976 & 3976 & 4526 & 4588 & 4738 & 4644 & 4773 & 4944 & 4753 \\
\hline Trinidad & 2623 & 2624 & 2629 & 2487 & 2481 & 2618 & 2683 & 2680 & 2483 & 2617 \\
\hline Jesús & 1866 & 1819 & 1899 & 1987 & 2028 & 2101 & 2028 & 2074 & 2082 & 2125 \\
\hline S. Carlos & 1678 & 1628 & 1663 & 1796 & 1864 & 1865 & 1977 & 2024 & 2074 & 2217 \\
\hline S. José & 1889 & 1986 & 2019 & 2132 & 2085 & 2162 & 2225 & 2310 & 2357 & 2338 \\
\hline Apóstoles & 1923 & 2055 & 2118 & 2241 & 2320 & 2405 & 2449 & 2522 & 2587 & 2656 \\
\hline Concepción & 2274 & 2337 & 2136 & 2601 & 2727 & 2860 & 2911 & 2912 & 2798 & 3029 \\
\hline Mạrtires & 2781 & 3075 & 3112 & 3189 & 3235 & 3282 & 3362 & 3217 & 3251 & 3218 \\
\hline La Mayor & 2082 & 2060 & 2128 & 2431 & 2393 & 2370 & 2446 & 2870 & 2445 & 2034 \\
\hline S. Javier & 1942 & 1946 & 1968 & 1999 & 2010 & 1875 & 1909 & 1898 & 1882 & 1861 \\
\hline S. Nicolás & 4245 & 3913 & 4255 & 4511 & 4724 & 4863 & 5031 & 416 & 2542 & 4278 \\
\hline S. Luis & 3371 & 3354 & 3037 & 3746 & 3783 & 3967 & 4121 & 3828 & 3802 & 4069 \\
\hline S. Lorenzo & 1838 & 1642 & 1729 & 1884 & 2091 & 2117 & 2321 & 1459 & 1852 & 1819 \\
\hline S. Miguel & 6898 & 6645 & 6635 & 7047 & 6229 & 6450 & 6460 & 1035 & 2972 & 4995 \\
\hline S. Juan & 3228 & 3271 & 3221 & 3707 & 3892 & 3977 & 4059 & 3347 & 3880 & 4070 \\
\hline Sto. Ángel & 5105 & 4858 & 5186 & 5275 & 5417 & 5421 & 5692 & 2531 & 3368 & 4095 \\
\hline Sto. Tomé & 2709 & 2793 & 2917 & 2755 & 2499 & 2880 & 3056 & 3042 & 3167 & 3277 \\
\hline S. Borja & 3493 & 3541 & 3435 & 3487 & 3232 & 2841 & 3018 & 1668 & 1934 & 3911 \\
\hline La Cruz & 2575 & 2410 & 2518 & 2625 & 2430 & 3573 & 3123 & 2982 & 3148 & 3239 \\
\hline Yapeyú & 6726 & 6400 & 6518 & 7360 & 7040 & 6910 & 7169 & 7597 & 7705 & 7418 \\
\hline
\end{tabular}

$1760-1776 / 1777$

\begin{tabular}{|l|l|l|l|l|l|l|l|l|l|l|}
\hline Misión & $\mathbf{1 7 6 0}$ & $\mathbf{1 7 6 1}$ & $\mathbf{1 7 6 2}$ & $\mathbf{1 7 6 3}$ & $\mathbf{1 7 6 4}$ & $\mathbf{1 7 6 5}$ & $\mathbf{1 7 6 7}$ & $\mathbf{1 7 6 8}$ & $\mathbf{1 7 7 2}$ & $\mathbf{1 7 7 6 / 7 7}$ \\
\hline Guazú & 2323 & 2263 & 2264 & 2233 & 3139 & 1985 & 1926 & 1916 & 1655 & \\
\hline La Fe & 4788 & 4335 & 4829 & 4901 & 4716 & 3943 & 3954 & 3054 & 2294 & \\
\hline S. Rosa & 3197 & 3236 & 3294 & 3292 & 2031 & 1934 & 2243 & 2243 & 2265 & \\
\hline Santiago & 4151 & 3806 & 3532 & 3071 & 2712 & 2711 & 2822 & 2822 & 3585 & 1404 \\
\hline
\end{tabular}


IHS. Antiguos jesuitas en Iberoamérica ISSN: 2314-3908

\begin{tabular}{|l|l|l|l|l|l|l|l|l|l|l|}
\hline Ytapúa & 4066 & 4064 & 4351 & 4353 & 4308 & 4542 & 4784 & 4784 & 4505 & \\
\hline Candelaria & 2644 & 2687 & 2724 & 2732 & 2817 & 2879 & 3064 & 3064 & 3077 & \\
\hline S. Cosme & 1540 & 1593 & 1535 & 2376 & 2206 & 2223 & 2337 & 2337 & 1709 & \\
\hline S. Ana & 5926 & 5606 & 5231 & 4091 & 4001 & 4161 & 4334 & 4334 & 5645 & \\
\hline Loreto & 4591 & 4669 & 4708 & 4659 & 4937 & 2395 & 2462 & 2462 & 2492 & 1451 \\
\hline S. I. Miní & 2986 & 3095 & 3222 & 3206 & 3074 & 3141 & 3306 & 3306 & 3738 & \\
\hline Corpus & 4698 & 4865 & 5149 & 4771 & 4280 & 4342 & 4587 & 4587 & 4887 & 4121 \\
\hline Trinidad & 2566 & 2689 & 2588 & 2465 & 2946 & 2633 & 2866 & 2365 & 1477 & \\
\hline Jesús & 2195 & 2232 & 2134 & 2294 & 2361 & 2278 & 2365 & 2286 & 2392 & \\
\hline S. Carlos & 2304 & 2351 & 2400 & 2248 & 2191 & 2265 & 2367 & 2377 & 1968 & \\
\hline S. José & 2421 & 2434 & 2399 & 2379 & 1955 & 2037 & 2122 & 2122 & 2180 & \\
\hline Apóstoles & 2757 & 2729 & 2780 & 2544 & 1993 & 2048 & 2127 & 2127 & 2277 & \\
\hline Concepción & 2996 & 3068 & 3192 & 3187 & 2724 & 2872 & 2839 & 1475 & 2935 & \\
\hline Mártires & 3328 & 3264 & 3225 & 3099 & 2220 & 1688 & 1662 & 1662 & 1724 & 704 \\
\hline La Mayor & 2076 & 2153 & 2554 & 2007 & 1228 & 1375 & 1475 & 2839 & 1398 & \\
\hline S. Javier & 1939 & 1883 & 1834 & 1831 & 1724 & 1511 & 1527 & 1527 & 1655 & \\
\hline S. Nicolás & 4321 & 4455 & 4429 & 4166 & 3925 & 4028 & 3811 & 4194 & 3741 & \\
\hline S. Luis & 4139 & 4313 & 4259 & 3705 & 3575 & 2207 & 3353 & 3500 & 3420 & \\
\hline S. Lorenzo & 1818 & 1847 & 1782 & 1672 & 1173 & 1185 & 1242 & 1412 & 1454 & \\
\hline S. Miguel & 5057 & 4534 & 4038 & 3202 & 2726 & 2864 & 3164 & 3556 & 2118 & \\
\hline S. Juan & 4050 & 4034 & 4017 & 4022 & 3805 & 3923 & 3791 & 4106 & 3087 & \\
\hline Sto. Ángel & 4091 & & 3863 & 3603 & 3112 & 2473 & 2362 & 2820 & 2039 & \\
\hline Sto. Tomé & 3485 & & 3427 & 3178 & 2511 & 1954 & 2172 & 2172 & 2317 & \\
\hline S. Borja & 3773 & 2957 & 2714 & 2602 & 2893 & 2755 & 2583 & 2761 & 2131 & \\
\hline La Cruz & 3342 & & 3044 & 3541 & 3568 & 3197 & 3243 & 3243 & 3402 & \\
\hline Yapeyú & 7765 & & 7470 & 7458 & 7501 & 7715 & 7974 & 7974 & 3322 & \\
\hline
\end{tabular}

1783-1803

\begin{tabular}{|l|c|c|c|c|c|c|c|c|c|c|c|}
\hline Misión & $\mathbf{1 7 8 3}$ & $\mathbf{1 7 8 4}$ & $\mathbf{1 7 8 5}$ & $\mathbf{1 7 9 3}$ & $\mathbf{1 7 9 7}$ & $\mathbf{1 7 9 8}$ & $\mathbf{1 7 9 9}$ & $\mathbf{1 7 9 9}$ & $\mathbf{1 8 0 1}$ & $\mathbf{1 8 0 2}$ & $\mathbf{1 8 0 3}$ \\
\hline Guazú & 800 & 896 & 867 & 1354 & & & & & 712 & 891 & 667 \\
\hline La Fe & 723 & & 1062 & 809 & & & & & 1233 & 1113 & 1049 \\
\hline S. Rosa & 1266 & 1254 & 1264 & 1910 & & & & 1228 & 1261 & 1193 & 1578 \\
\hline Santiago & 1119 & & 1215 & 1412 & & & & 1289 & 1262 & 1322 & \\
\hline Ytapúa & 3037 & 3381 & 2889 & 2066 & & 2850 & 2029 & 2244 & 2131 & 1789 & 1846 \\
\hline Candelaria & 1513 & 1935 & 1748 & 1490 & & 1433 & 1365 & & 1343 & 1334 & 1400 \\
\hline S. Cosme & 1103 & 1086 & 1111 & 1550 & & & & 939 & 60 & 50 & 854 \\
\hline S. Ana & 1834 & 1753 & 1747 & 1454 & & 1307 & 1286 & 1329 & 1293 & 1464 & 1310 \\
\hline Loreto & 1472 & 1418 & 1457 & 1261 & & 1276 & 1223 & 1212 & 1164 & 1046 & 1067 \\
\hline
\end{tabular}




\begin{tabular}{|l|r|r|r|r|r|c|c|c|c|c|c|}
\hline S. I. Miní & 1021 & 640 & 798 & 664 & & 739 & 790 & 71 & 06 & 921 & 898 \\
\hline Corpus & 2727 & 2484 & 2574 & 1946 & & 2344 & 2345 & 2287 & 2335 & 2443 & 2184 \\
\hline Trinidad & 1101 & 1116 & 1097 & 997 & & & 811 & 937 & 877 & 851 & 782 \\
\hline Jesús & 1306 & 1747 & 1302 & 1066 & & 908 & 736 & 981 & 1036 & 700 & 847 \\
\hline S. Carlos & 977 & 1343 & & 1023 & 996 & 1001 & 995 & & 1013 & 1010 & \\
\hline S. José & 1007 & 1288 & & 1086 & 869 & 905 & 856 & & 865 & 803 & 965 \\
\hline Apóstoles & 1571 & 2024 & & 2052 & 1459 & 1438 & 1242 & & 1914 & 1058 & 1387 \\
\hline Concepción & 1950 & 2327 & & 1349 & 1138 & 1037 & 1060 & & 1127 & 975 & 906 \\
\hline Mártires & 1197 & 1321 & & 892 & 751 & 715 & 681 & & 708 & 605 & 609 \\
\hline La Mayor & 978 & 840 & & 690 & 609 & 597 & 603 & & 559 & 73 & 549 \\
\hline S. Javier & 1379 & 1242 & & 895 & 1058 & 1015 & 1018 & & 959 & 1036 & 1028 \\
\hline S. Nicolás & 3667 & 3667 & & 2984 & 2443 & 2370 & 2381 & & 2406 & & \\
\hline S. Luis & 3500 & 3500 & & 3312 & 2571 & 2790 & 2463 & & 2776 & & \\
\hline S. Lorenzo & 1273 & 1273 & & 1171 & 1070 & 1096 & 963 & & 1037 & & \\
\hline S. Miguel & 1973 & 1973 & & 2334 & 1850 & 1772 & 1738 & & 1664 & & \\
\hline S. Juan & 2338 & 2388 & & 2018 & 1476 & 1004 & 1323 & & 1292 & & \\
\hline Sto. Ángel & 1926 & 1968 & & 1448 & 990 & 984 & 782 & & 1092 & & \\
\hline S. Tomé & 1837 & & & 1433 & 1569 & 1614 & 1687 & & 1786 & 1835 & 1910 \\
\hline S. Borja & 2906 & 2712 & & 2154 & 2403 & 2267 & 2284 & & 2413 & & \\
\hline La Cruz & 3746 & & & 3871 & 3331 & & 3165 & & 3238 & 3458 & 3542 \\
\hline Yapeyú & 4747 & 4739 & & 5170 & 3990 & 4025 & 4095 & & 4948 & 4669 & \\
\hline
\end{tabular}

La Población de Jesús María de los Guenoas

\begin{tabular}{|l|c|c|c|c|c|c|c|c|c|}
\hline Año & $\mathbf{1 6 9 0}$ & $\mathbf{1 6 9 4}$ & $\mathbf{1 6 9 8}$ & $\mathbf{1 7 0 2}$ & $\mathbf{1 7 0 5}$ & $\mathbf{1 7 1 4}$ & $\mathbf{1 7 1 5}$ & $\mathbf{1 7 1 6}$ & $\mathbf{1 7 1 7}$ \\
\hline & 334 & 298 & 200 & 200 & 288 & 357 & 280 & 307 & 283 \\
\hline
\end{tabular}

\section{Referencias Documentales.}

Anua del Pueblo de S[a]n Fern[and]o Desde el Año 1753, Archivo General de la Nación, Buenos Aires, Sala 9-10-6-10.

Anua de la Reducción de San Geronimo de Abipones, desde 1 de Enero de 1761 hasta 1 del mismo mes de 1762, Archivo General de la Nación, Buenos Aires, Sala 910-6-10.

Annua Enumeratio Reductionum Anni 1755, Archivo General de la Nación, Buenos Aires, Sala 9-6-10-6.

Annua Enumeratio Reductionum Anni 1757, Archivo General de la Nación, Buenos Aires, Sala 9-6-10-6.

Annua Enumeratio Reductionum Anni 1760, Archivo General de la Nación, Buenos Aires, Sala 9-6-10-6. 
Carta Anua 1756-1762, Biblioteca Nacional, Archivo General de la Nación, Buenos Aires, Ms. 4421 lat.

Catologo de la numeración annual de las Doctrinas del Río Paraná Año 1736, Archivo General de la Nación, Buenos Aires, Sala 9-6-9-7.

Catologo de la numeración annual de las Doctrinas del Río Paraná Año 1739, Archivo General de la Nación, Buenos Aires, Sala 9-6-9-7.

Catologo de la numeración annual de las Doctrinas del Río Paraná Año 1740, Archivo Nacional, Asunción Paraguay.

Catologo de la numeración annual de las Doctrinas del Río Paraná Año 1750, Archivo General de la Nación, Buenos Aires, Sala 9-6-9-7.

Catologo de la numeración annual de las Doctrinas del Río Paraná Año 1752, Archivo General de la Nación, Buenos Aires, Sala 9-6-9-7.

Catologo de la numeración annual de las Doctrinas del Río Paraná Año 1754, Archivo General de la Nación, Buenos Aires, Sala 9-6-9-7.

Catologo de la numeración annual de las Doctrinas del Río Paraná Año 1762, Archivo General de la Nación, Buenos Aires, Sala 9-6-9-7.

Catologo de la numeración annual de las Doctrinas del Río Paraná Año 1763, Archivo General de la Nación, Buenos Aires, Sala 9-6-9-7.

Catologo de la numeración annual de las Doctrinas del Río Paraná Año 1765, Archivo General de la Nación, Buenos Aires, Sala 9-6-9-7.

Difuntos de Viruelas, Archivo General de la Nación, Buenos Aires, Sala 9-6-10-6.

Enumeratio Annua, 1733, Archivo General de la Nación, Buenos Aires, Sala 9-6-9-6.

Enumeratio Annua, 1736, Archivo General de la Nación, Buenos Aires, Sala 9-6-9-7.

Familias, y Almas de los 7 Pueblos de la otra banda del Uruguay, y los Pueblos en que están repartidas, 1763, 1764, y 1765, Archivo General de la Nación, Buenos Aires, Sala 9, 6-10-6.

Las Familias de los 3 Pueblos S Luis, S Juan, y Sto Ángel están repartidas en los Pueblos Siguientes, Archivo General de la Nación, Buenos Aires, Sala 9-6-10-6.

Estado de La Reducción de San Gerónimo de Abipones, En El Año 1758. Archivo General de la Nación, Buenos Aires, Sala 9-10-6-10.

Expediente s[ob]re la Epidemia de Viruelas q[u]e acometió a los Pueblos de S[an] Joséph y Apóstoles, Archivo General de la Nación, Buenos Aires, Sala 9-8-3-52.

Littre Annuae Provincia Paraguarie Anno 1735, Archivum Romanum Societatis Iesu, Ciudad Vaticano.

Muertos de la Epidemia de Viruelas este Año de 1764, AGN, Sala 9-6-10-6.

Padrón de Nuestra Señora de los Reyes de Yapeyú (1771), Archivo General de la Nación, Buenos Aires, Sala 9-18-8-7.

Santa Rosa Registro de bautismos, Archivo Parroquial de Santa Rosa, Paraguay.

Vicente Ximénez, Villa de Concepción, abril 26, 1790, Lista de los Yndios Guaranis procedentes de los Pueblos de Misiones que se hallan en las Villas de Concepción del Uruguay, San Joséph de Gualeguayes y San Antonio del Gualeguay, y sus partidos, Archivo General de la Nación, Buenos Aires, Sala 917-3-6. 


\section{Referencias Bibliográficas}

Borah, Woodrow y Sherburne F. Cook (1960), The Population of Central Mexico in 1548: An Analysis of the Suma de visitas de pueblos (Berkeley y Los Angeles: University of California Press.

Carbonell de Masy, S.J., Rafael (1992), Estrategias de desarrollo rural en los pueblos guaraníes, 1609-1767, Barcelona: Instituto de Cooperación Iberoamericana.

Carbonell de Masy, S.J., Rafael, Teresa Blummers, y Norberto Levinton (2003), La reducción jesuítica de Santos Cosme y Damián: Su historia, su economía y su arquitectura, 1633-1797, Asunción: Markografik.

Cook, Noble David (1998), Born to die: disease and New World conquest, 1492-1650, Cambridge: Cambridge University Press.

Cook, Sherburne y Woodrow Borah (1948), The Population of Central Mexico in 1548: An Analysis of the Suma de visitas de pueblos, Berkeley y Los Angeles: University of California Press.

--------- (1971-1979), Essays in Population History, 3 volumenes, Berkeley and Los Angeles: University of California Press.

Del Paso y Troncoso, Francisco (1905), Papeles de la Nueva España. Segunda series geografía y estadística, tomo I suma de visitas por orden alfabético, Madrid: Tip. Sucesores de Rivadenyera.

Denevan, William (editor) (1976-1992), The Native Population of the Americas in 1492, Madison: University of Wisconsin Press.

Fernández del Castillo, Francisco (1985), Los Viajes de Don Francisco Xavier de Balmis, México, D.F.: Sociedad Médica Hispano- Mexicana.

Flinn, Michael (1980), The European Demographic System, 1520-1820, Baltimore: The Johns Hopkins University Press.

Furlong Cardiff, S.J., Guillermo (1962), Misiones y sus pueblos de Guaraníes, Buenos Aires: Tip. Editora.

Ganson, Barbara (2003), The Guarani Under Spanish Rule in the Río de la Plata, Stanford: Stanford University Press.

Henry F. Dobyns, Henry F. (1983), Their Numbers Become Thinned: Native American Population Dynamics in Eastern North America, Knoxville: University of Tennessee Press.

Henige, David (1978), "On the Contact Population of Hispaniola: History as Higher Mathematics,” Hispanic American Historical Review n ${ }^{\circ} 58$.

Hernández, Juan Luis (1999), "Tumultos y motines. La conflictividad social en los pueblos guaraníes de la región misionera, 1768-1799,” Memoria Americana 8.

Hernández S.J., Pablo (1913), Organización social de las Doctrinas Guaraníes de la Compañía de Jesús, 2 volúmenes, Barcelona: Gustavo Gili Editor.

Jackson, Robert H. (1981), “The 1781-1782 Smallpox Epidemic in Baja California,” Journal of California and Great Basin Anthropology $\mathrm{n}^{\circ} 3$.

(1994), Indian Population Decline: The Missions of Northwestern New Spain, 1687-1840, Albuquerque: University of New Mexico Press.

- (2001), “A Frustrated Evangelization: The Limitations to Social, Cultural and Religious Change Among the "Wandering Peoples" of the Missions of the 
Central Desert of Baja California and the Texas Gulf Coast,” Fronteras de la Historia, $\mathrm{n}^{\circ} 6$.

(2004a), "Demographic Patterns in the Jesuit Missions of the Río de la Plata Region: The Case of Corpus Christi, 1622-1802," Colonial Latin American Historical Review, $\mathrm{n}^{\circ} 13$.

(2004b), "Mortality Crises in the Jesuit Missions of Paraguay, 1730-1740," World History Review $\mathrm{n}^{\circ} 1$.

- (2004c), "Una mirada a los patrones demográficos de las misiones jesuitas de Paraguay,” Fronteras de la Historia n ${ }^{\circ} 9$.

(2004d), "A Colonization Born of Frustration: Rosario Mission and the Karankawas," Journal of South Texas $\mathrm{n}^{\circ} 17$.

(2005), Missions and Frontiers of Spanish America: A Comparative Study

of the Impact of Environmental, Economic, Political, and Socio-Cultural Variations on the Missions in the Río de la Plata Region and on the Northern Frontier of New Spain, Scottsdale: Pentacle Press.

- (2008), "The Population and Vital Rates of the Jesuit Missions of Paraguay 1700-1767,” Journal of Interdisciplinary History $n^{\circ} 28$.

(2013), "The Chichimeca Frontier and the Evangelization of the Sierra Gorda, 1550-1779”, Estudios de Historia Novohispana, ${ }^{\circ} 47$.

Livi-Bacci, Masimo (2005), Conquest: the Destruction of the American Indios, Cambridge: Polity Press.

(2006) "The Depopulation of Hispanic America After the Conquest", Population and Development Review $\mathrm{n}^{\circ} 32$.

Maeder, Ernesto (editor) (1990), Cartas anuas de la Provincia Jesuítica del Paraguay, 1632-1634, Buenos Aires: Academia Nacional de la Historia.

(1996), Una Aproximación a las Misiones guaraníticas, Buenos Aires, Universidad Católica Argentina.

Martínez Martín, Carmen (1998), “Datos estadísticos de población sobre las misiones del Paraguay, durante la demarcación del Tratado de Límites de 1750,” Revista Complutense de Historia de América $\mathrm{n}^{\circ} 24$.

Page, Carlos (2012), Las otras reducciones jesuíticas: Emplazamiento territorial, desarrollo urbano y arquitectónico entre los Siglos XVII y XVIII, Saarbrücken, Alemania: Editorial Académica Española.

Porto, Aurelio (1954), Historia das Missões Orientais, 2 volúmenes, Porto Alegre: Livraria Selbach.

Rosenblat, Ángel (1935), “El desarrollo de la población indígena de América,” Tierra firme $\mathrm{n}^{\circ} 1$.

(1967), La población de América en 1492: viejos y nuevos cálculos, México, DF: El Colegio de México.

- (1976), “The Population of Hispaniola at the Time of Columbus," en Denevan (comp.).

Rosso, Cintia Natalia (2011), "Epidemias de viruela en las reducciones chaqueñas de abipones y mocovies durante siglo XVIII,” Revista EA n ${ }^{\circ} 2$.

Saeger, James (2000), The Chaco Mission Frontier: The Guaycuruan Experience, Tucson: University of Arizona Press. 
Sanders, William T. (1976), “The Population of the Central Mexican Symbiotic Region, the Basin of Mexico, and the Teotihuacán Valley in the Sixteenth Century,” en Denevan (comp.).

Sarreal, Julia (2014), The Guarani and Their Missions: A Socioeconomic History, Stanford: Stanford University Press.

Simpson, Lesly B. (1950), The Encomienda in New Spain, Berkeley and Los Angeles: University of California Press.

Vives Azancot, Pedro (1982), "Entre el esplendor y la decadencia: La población de misiones (1750-1759)”, Revista de Indias n ${ }^{\circ} 42$.

Wrigley, E.A. y Robert Schofield (1981), The Population History of England, 15471871: A Reconstruction, Cambridge: Harvard University Press.

Zambardino, Rudolph A. (1978), "Critique of David Henige's 'On the Contact Population of Hispaniola: History as Higher Mathematics,'” Hispanic American Historical Review $\mathrm{n}^{0} 58$.

(1980), “Mexico’s Population in the Sixteenth Century: Demographic Anomaly or Mathematical Illusion?” Journal of Interdisciplinary History $n^{0} 1$. 